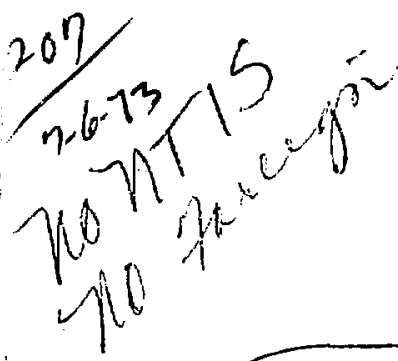

th. $2 / 2$

\title{
SIMULATION OF THE LLL BENIOFF SEISMIC SYSTEM
}

\author{
M. D. Denny
}

May 4, 1973

Prepared for U.S. Atomic Energy Commission under contract No. W-7405-Eng-48

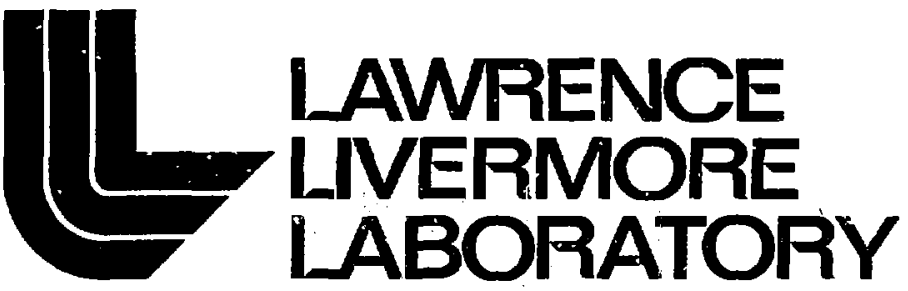

University of California/Livermore 
Notice

"This report was prepared as an account of work sponsored by the United States Government. Neither the United States no the United Slates Atomic Enetgy Commission, nor any of their empioyes, nor any of their contractors, subcontmetors, or their employees, makes any warranty, express or implied, of assumes employes, makes any waranty, express or implied, or assumes any leal tabinty or resporsibihy for the accuracy, conspletene or usefunness of any infortuation, apparatus, product or process disclosed, or represents that its use would not infringe privately owned tiphts"

Printed in the United States of America Available from

National Technical Information Service

U.S. Department of Commerce 5285 Port Royal Road

Springfield, Virginia 22151

Price: Printed Copy $\$$; Microfiche $\$ 0.95$

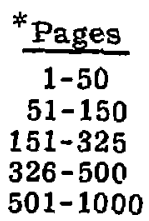

NTIS

Selling Price

$\$ 4.00$

$\$ 5.45$

$\$ 7.60$

$\$ 10.60$

501-1000

$\$ 13.60$ 


\title{
노
}

\section{LAMRENCE LNERMORE LABORATOFY}

universityor Calfomia Livermora, Calfomin/34550

\section{UCRL -51318 \\ SIMULATION OF THE LLL BENIOFF SEISMHC SYSTEM}

\author{
M. D. Denny
}

MS. date: May 4, 1973

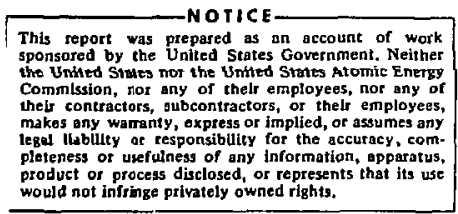




\section{Contents}

\section{Abstract}

Introduction

Description of the System

Mathematical Models

Seismometer with Resistive Load

Galvanometer with Resistive Load

Seismometer-Galvanometer Combination

PTA Filter

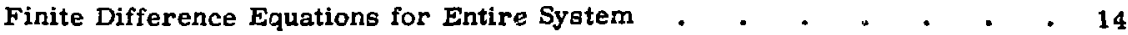

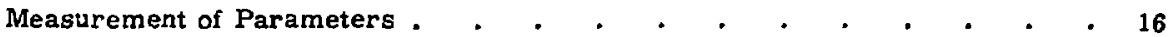

Seismometer

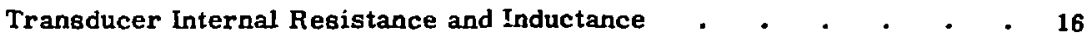

Natural Damping and Free Period . . . . . . . . . 17

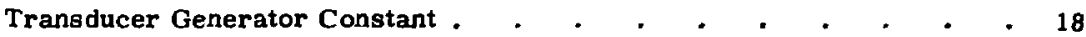

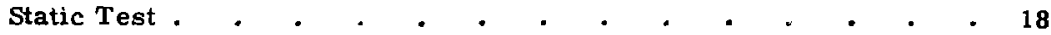

Dynamic Test . . . . . . . . . . . . . . . 20

Calibration Coil Motor Constant $\quad$ - . . . . . . . 21

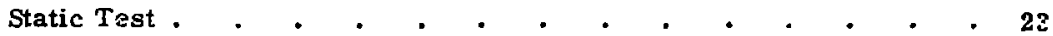

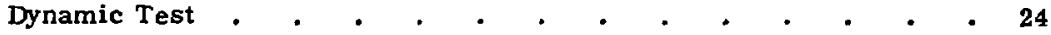

Ball Lift Matching Test . . . . . . . . . . . 25

Damping and Line Resistances . . , . . . . . . . 27

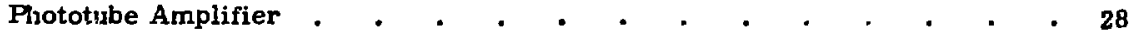

Pttenuator . . . . . . . . . . . . . . . . 28

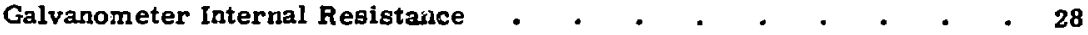

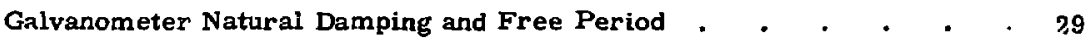

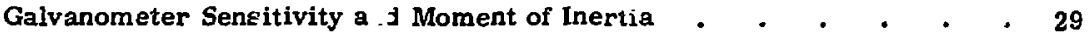

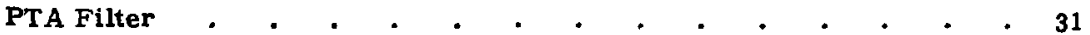

Film Recorder . • . . . . • . • • . . . . 31

Galvanometer Internal Resistance . . . . . . . . . . 31

Galvanometer Natural Damping and Free Period . . . . . . 31

Galvanoineter Termination . • . • . . • . . . . 32

Galvasometer Seısitivity and Mement of Inertia . - . . . . 32

Recursive Code Calculations . . . . . . . . . . . . 34

Code Verification and Parameter Modiríications . . . . . . . 34

Seismometer . • . . . • • • • . . . • . 34

PTA Galvanometer and Filter . . . . . . . . . . 37

Film Recorder Galvanometers . . . . . . . . . . . 40 
Seismometer and Film Recorder Damping: Criteria and Parameter Study

Free Period Tests

Ball Lift Tests

Frequency Response Tests

Comparison of Digitally Filtered Data wit's Film Data Scaling of Filtered Data

Filtered Data Compared with Film Data

Conclusions

Acknowledgments

Appendix. Benioff Recursive Filter 


\title{
SIMULATION OF THE LLL BENIOFF SEISMIC SYSTEM
}

\begin{abstract}
For the past decade the Laboratory has conducted a seismic yield measurement program in support of the nuclear testing program at the Nevada Test Site. Initially, two stations were equipped with a short-period vertical-component seismometer and film recurder system designed by Hugo Benioff. Later this system was replaced by a long-period broad-band telemetry system. Since much of the data currently used in the seismic yield determination consists of data recorded on the Benioff system, an equivalent Benioff signa! must be filtered from the data recorded on the broad-band system. To determine that signal, the Benioff system was removed from storage and set up for critical laboratory measuremsnts. Unfortunately the damping of the seismometer and of the film recorder galvanometers could not be reconstructed in the lab. Consequently, it was necessary to deduce these values from parameter studies a'id from routine response tests conducted in the field prior to the recording of a nuclear event. The parameter studies were made with a recursive filter code that simulates the Benioff system. The damping values finally arrived at are compromises as the field tests showed that considerable variation existed from event to event. Nevertheless, the recursive filter code satisfactorily reproduced the Benioff data from the broad-baild data when tested against actual Benioff data.
\end{abstract}

\section{Introduction}

For the past decade the Laboratory has conducted a seismic yield measurement program in support of the nuclear testing program at the Nevada Test Site. Initially two stations, one near Mina, Nevada and the other near Kanab, Utah, were equipped with the short period vertical component seismometer and film recorder systern designed by Hugo Benioff of $\mathrm{Cal}$ Tech. They were built by Geotecil Corporation of Garland, Texas. The equipment was operated and maintained in the field on a courtesy basis by personnel of the Geotech Corporation under contract to the Air Force Technical Application Center (AFTAC) as these stations were a part of AFTAC's Long Range Seismic Measurement (LRSM) program. This film recorder system was later replaced by a long period, broad-band, telemetry system which is currently in use at both of the two original stations plus two new ones, one near Landers, California, and one near Elko, Nevada.

Much of the data base currently used in the seismic yield determinations consists of data recorded on the Benioff system. Consequently, an equivalent Benioff signal 
must be filtered from the data recorded on the broad-banc'system. Originally, the filter only approximated the overall system response without regard for the responses of the individual components. Consequently, an empirical correction factor was needed to convert the filtered amplitudes into equivalent Benioff amplitudes. This correction factor was arrived at by a linear regression fit to

$$
\log (\text { Benioff amplituae })=\mathrm{E} 1+\mathrm{E} 2 \log (\text { filtered amplitude })
$$

for twenty events recorded on hoth systems. The standard deviation from this fit was about $7.5 \%$. As this was not a completely satisfactory situation, we felt that a new filter which simulates each part of the system wovld do a better job.

Tu fill this need we designed and built an electrical filter, mainematically modeled the system, and then wrote a recursive, digital filter code. All of this requires considerable knowledge of the system and, therefore, it was removed from storage and critical laboratory measurements were made.

The system galvanometers are governed by second rarder differential equations which can be described satisfactorily with the results of a free period and relative amplitude response curve. However, the seismometer is governed by a third order differential equation and is not as easily characterized. To describe the seismonieter we need to know the internal resistance, inductance, and generator constant of the magnetic variable-reluctance circuit, the mass of the moving hody, its naturai damping, and its natural frequency when the magnetic circuit is open. The opportunity to test the system also allowed us to determine the motor constant of the calibration coil and the effect that channel differences had on event data.

\section{Description of the System}

The seismometer, shown in Fig. 1, consists of a large steel cylinder which is free to move along its vertical axis and which is supported by a coil spring located in the center of the cylinder. This cylinder is restrained from any horizontal or torsional motion by six small leaf springs, three at the top and three at the bottom. The bottom of the cylinder is attached to one-half of the variable reluctance transuacer. The other half is attached to the frame and is stationary. The two halves are separated by an air gap. When the part attached to the cylinder moves, the gap between the two l'arts becomes unequal and produces a variable reluctance in the magnetic circuit. This in turn produces a voltage in the coils such that the output of the transducer is proportional to the velocity of the mass of the seismometer.

The damping of the seismometer is controlled by a variable resistor located in a unit called the "Line Termination Module" and connected in series with the transducer. See Fig. 2 for a schematic of the system. The terminal voltage of this unit is amplified by a photo-tube amplifier (PTA) which consists of a light source, a mirror 


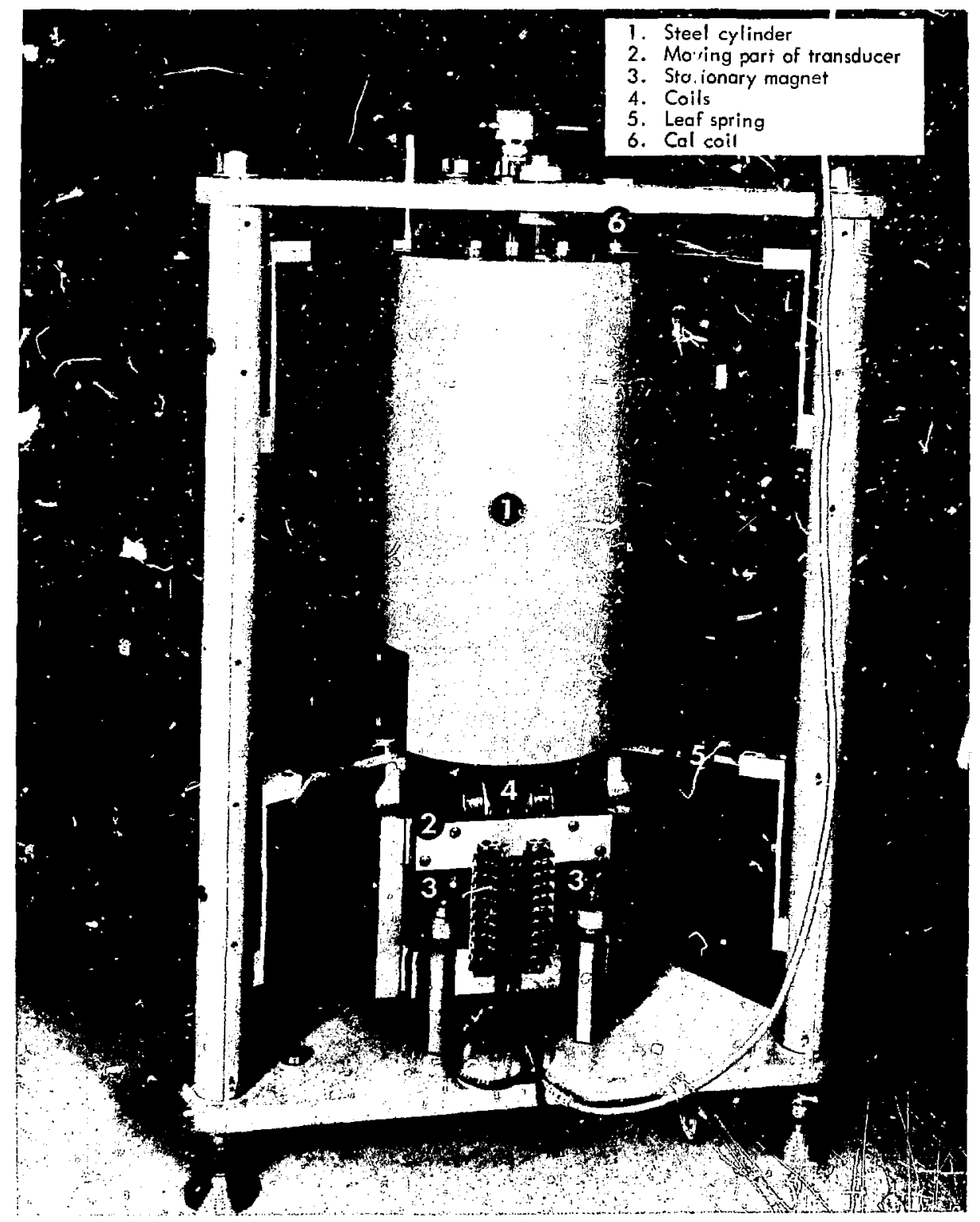

Fig. 1. Benioff Seismometer. 

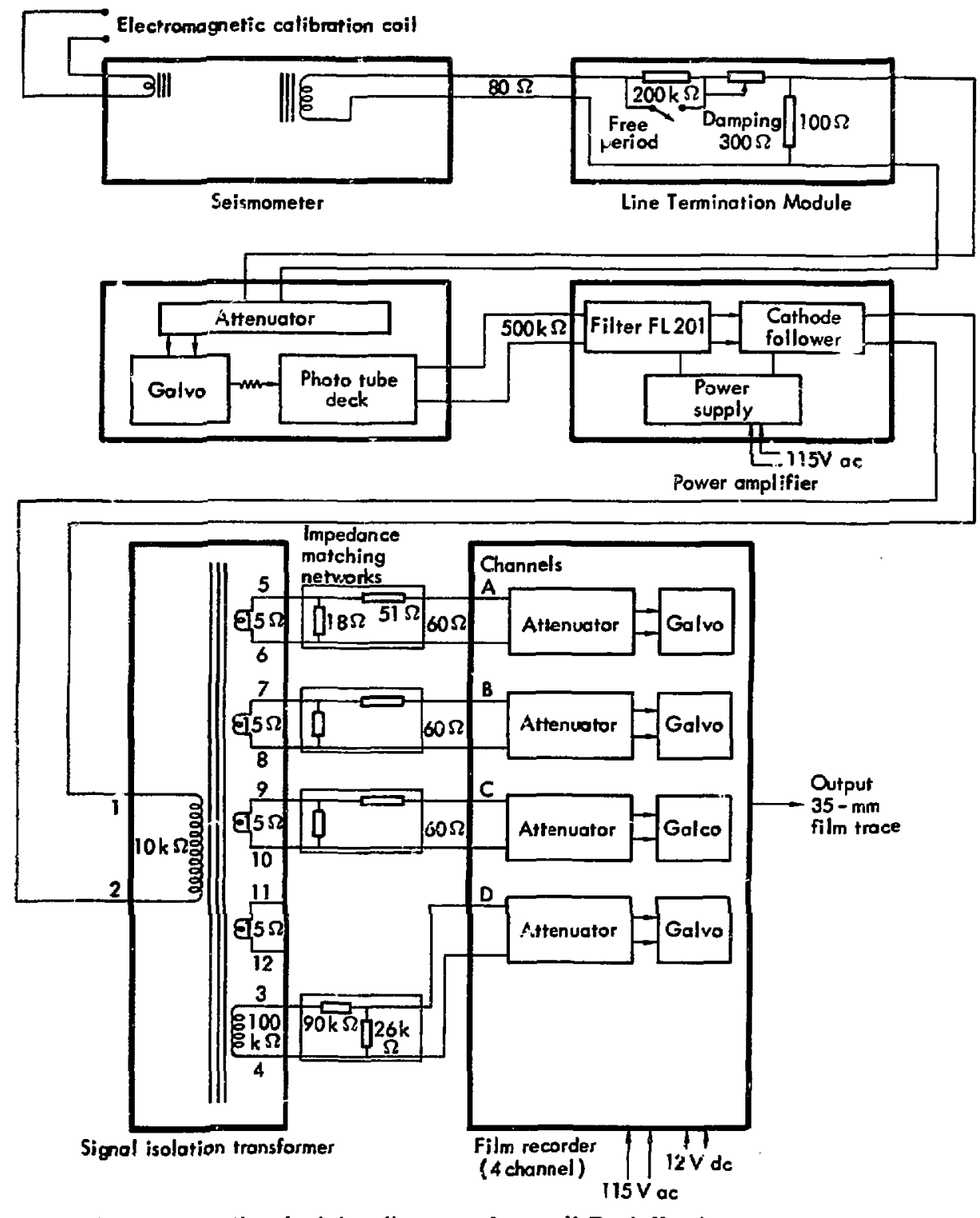

Fig. 2. Functional wiring diagram of overall Benioff seismometer system. 
mounted on a galvanometer and a photo tube deck. The principle of operation is that a voltage on the input causes an angular rotation of the galvanometer which, in turn, causes the light reflected from the mirror to move across the photo deck. The photo deck then produces a voltage which is proportional to the deflection of the light spot. The net effect is to amplify the low frequencies more than the high (above $5 \mathrm{~Hz}$ ).

Before driving the galvanometer lucated in the film-recorder, the signal from the photo deck is further filtered by a band pass filter, located in the amplifier power supply. The film recorder operates on much the same principle as the PTA except that, instead of the deflection of the light spot being detected by a photo deck, the light spot exposes $35-\mathrm{mm}$ film which is mounted on a drum. This drum makes one revolution every $6 \mathrm{~min}$ and travels horizonially $0.8 \mathrm{~mm}$ during each revolution, so there are up to 30 traces on each film strip.

There are two ways to calibrate the system. In the primary method we shake the mass by driving a small electromagnetic coil (calibrated coil, item 6 of Fig. 1) with a current of known amplitude and frequency. The second way is to drop a small known weight onto the mass. This method (known as the ball lift) is of limited value except as a quick check on the damping ratio of the seismometer.

\section{Mathematical Models}

\section{SEISMOMETER WITH RESISTIVE LOAD}

Because the Benioff seismometer hi 3 a higher inductive load than resistive load, it cannot be described by a second order differential equation, as can most seismometers. A second order differential equation predicts a linear relationship between the voltage output and sinusoidal input ground displacement for frequencies above the natural frequency. On the other hand, shake table tests for the Benioff show a constant relationship for these conditions. To obtain agreement between practice and theory a third order differential equation is needed. It is derived by including the inductive load of the magnetic circuit as follows.

The equation of motion is

$$
M \ddot{x}+D \dot{x}+C x+K_{s} i=-M z
$$

where $\mathrm{x}$ is the relative displacement between the mass and frame, $\mathrm{z}$ is the absolute displacement of the frame, $M$ is the mass, $D x$ is the restoring force resulting from internal viscous damping, $C x$ is the restoriing force of the spring, and $K_{s} i$ is the electromagnetic restoring force of the current flowing through the transducer coils. The generator constant $\left(\mathrm{K}_{\mathrm{s}}\right.$; is in $\mathrm{N} / \mathrm{A}$ and $\mathrm{i}$ is the current in the trangducer's coils. Now, divide Eq. (1) by $M$ and let $\omega_{S}^{2}=C / M$ and $2 h_{s} \omega_{s}=D / M$, where $\omega_{S}$ is the undamped 
natural circular frequensy and $h_{5}$ is the coefficient of critical damping under no load. This results in the following expression

$$
x+2 h_{s} \omega_{s} x^{2}+\omega_{s}^{2} x+\frac{K}{M} i=-z .
$$

The current $i$ is found from the circuit equations for the transducer given below

$$
K_{s} \dot{x}=i\left(R_{s}+S\right)+L \dot{i}
$$

where $\mathrm{K}_{\mathrm{g}} \mathrm{X}$ is the voltage generated by the motion of the mass relative to the frame, $i\left(R_{s}+S\right)$ is the voltage loss in the internal resistance of the coils $\left(R_{s}\right)$, and $S$ and $I i$ (the extercal damping load) are the voltage losses resulting from coil inductance.

The frequency response of the system can be found directly by taking the Fourier transforms of Eqs. (2) and (3) as follows, where the bar denotes the transformed variable and $j=\sqrt{-1}$. Equation (3) becomes

$$
j \omega K_{s} \bar{x}=\bar{i}(R+j \omega L)
$$

where $R=R_{S}+S$ and (2) becomes

$$
\bar{x}\left(-\omega^{2}+2 h_{s} \omega_{s} j \omega+\omega_{s}^{2}\right)+\frac{K}{M} \bar{i}=\omega^{2} \bar{z} .
$$

The transfer function (the ratio of the relative motion of the mass to the absolute motion of the frame) can now be found by substituting (4) into (5)

$$
\text { Transfer Function }=\frac{\bar{x}}{\bar{z}}=\frac{\omega^{2}}{-\omega^{2}+\left(2 h_{s} \omega_{s}+\frac{K_{s}^{2}}{M(R+j \omega L)}\right) j \omega+\omega_{s}^{2}} .
$$

Equation (6) shows that the transfer function is the same for displacement, velocity, and acceleration. This is shown simply by multiplying the top and bottom of the lefthand side by $-i \omega$ and $\omega^{2}$ respectively. It also shows that the damping term is a complex quantity,

$$
2 h_{s} w_{s}+\frac{K_{s}^{2}}{M(R+j \omega L)} .
$$

Seismologists often use magnification and velocity sensitivity to describe instrukent response and to reduce response output to physical quantities. They are defined below: 


$$
\text { Magnnification }(M) \equiv \frac{\text { output }}{\text { input ground displacement }}
$$

Velocity Sensitivity (V.S.) $\equiv \frac{\text { output }}{\text { input ground velocity }}$

Both are applicable to sinusoidal input ground motion, but velocity sensitivity is more meaningful for general ground motion since the transducer is basically sensitive to velocity. The units of the output are arbitrary and can be measured by displacement on a strip chart or film record or by a voltage or current. If, as in the case of the shake table test to be discussed later, the output is defined as the voltage across the external load, then

$$
M=\left|\frac{\bar{i}}{\bar{z}}\right| \quad \text { and } V, S .=\left|\frac{S \bar{i}}{j \omega \bar{z}}\right| \text {. }
$$

or using Eq. (4)

$$
M=\left|\frac{S K_{s} j \omega \bar{x}}{(R+j \omega L) \bar{z}}\right|=\left|\frac{S K_{s} j \omega}{(R+j \omega L)}\right| \quad \text { |Transfer F'unction } \mid
$$

and

$$
\text { V.S. }=\left|\frac{M}{j \omega}\right|=\left|\frac{S_{s}}{\bar{R}+j \omega L)}\right| \quad \mid \text { Transfer Function } \mid
$$

Equation (11), after taking the absolute value, or modulus, becomes

$$
M=\frac{S K_{F}}{R} \frac{\omega^{3}}{\left[\left(\omega_{s}^{2}-\omega^{2}-2 h_{s} \omega_{s} \omega^{2} \frac{L}{R}\right)^{2}+\omega^{2} \frac{L^{2}}{R^{2}}\left(\omega_{s}^{2}-\omega^{2}+2 h_{s} \omega_{s} \frac{R}{I}+\frac{K_{s}^{2}}{L M}\right)^{2}\right]^{1 / 2}} \cdot
$$

Equation (13) will be used later to reduce the results of the shake table test; it is the most convenient form of the response function for this application, since displacement of the shake table can be measured directly. For small frequencies $\left(\omega<\omega_{B}\right)$, it can be seen from Eq. (13) that the magnification is proportional to $\omega^{3}$ while for high frequencies $\left(\omega>\omega_{s}\right)$, it approaches a constant value, $S K_{s} / L$.

\section{GALVANOMETER WITH RESISTIVE LOAD}

Unlike the seismometer, the galvanometer can be represented satisfactorily by a second order differential equation since its internal inductive load is small 
compared to its resistive load. The equation of motion is

$$
I \ddot{\theta}+D \theta+K \dot{\theta}=T_{g} i,
$$

where $\theta$ is the angular deflection of the galvanometer, $I$ is the moment of inertia, $I \theta$ is the inertial torque, $D \dot{A}$ is the internal viscous damping torque, $\mathrm{K}$ is the torque rate, $\mathrm{K} \theta$ is the restoring spring torque, $\mathrm{T}_{g}$ is the galvanometer sensitivity, $\mathrm{T}_{\mathrm{g}} \mathrm{i}$ is the driving torque, and $i$ is the driving current.

The circuit equation is

$$
e_{\text {in }}=i\left(R_{g}+R_{x}\right)+T_{g} \dot{\theta}_{,}
$$

where $e_{\text {in }}$ is the driving voltage, $i R_{g}$ is the voltage loss resulting from the internal resistance of the galvanometer $\left(R_{g}\right)$, in $x$ is the voltage loss resulting from the external resistance used to control the damping $\left(R_{x}\right)$, and $T_{g} \dot{\theta}$ is the voltage loss resulting from the deflection of the galvanometer. Again the frequency response can be found directly from the Fusurier transformation of Eqs. (14) and (15)

$$
\begin{aligned}
& \bar{\theta}\left(\omega_{g}^{2}-\omega^{2}+2 h_{g} \omega_{g} j \omega\right)=\frac{T_{g}}{\mathrm{i}} \\
& \overline{\mathrm{e}}_{\mathrm{in}}=\overline{\mathrm{i}}\left(\mathrm{R}_{\mathrm{g}}+\mathbf{R}_{\mathrm{x}}\right)+j \omega \bar{\theta} \mathrm{T}_{\mathrm{g}},
\end{aligned}
$$

where $\omega_{g}^{2}=\mathrm{K} / \mathrm{I}$, the natural or free angular frequency of the galvanomer under no load, and where $2 h_{g} \omega_{g}=D / I$, the corresponding damping term. Solving for $\overline{\mathrm{i}}$ in Eq. (17) and substituting the result in Eq. (16) yields the galvanometer transfer function

$$
\frac{\bar{\theta}}{\overline{\mathrm{e}}_{\text {in }}}=\frac{\left(\mathrm{T}_{g} / \mathrm{I}\right)}{\omega_{g}^{2}-\omega^{2}+j \omega\left(2 h_{g} \omega_{g}+\frac{T_{g}^{2} / I}{R_{g}+R_{x}}\right)} .
$$

The damping can be defined as a fraction of critical damping

$$
\eta=h_{g}+\frac{r_{g}^{2} / I}{2 \omega_{g}\left(R_{g}+R_{x}\right)},
$$

where $\eta=1$ for critical damping. The relative amplitude $r u s p o n s e$ is found by taking the absolute value of Eq. (18) 


$$
\left.\frac{b \bar{\theta}}{\mid \bar{e}_{\text {in }}}\right|^{\frac{\omega_{g}^{2} I}{T_{g}}}=\frac{1}{\left[\left(1-\frac{\omega^{2}}{\omega_{g}^{2}}\right)^{2}+4 \frac{2 \omega^{2}}{\omega_{g}^{2}}\right]^{1 / 2}} .
$$

which approaches 1 for $\omega<\omega_{g}$ and approaches $\omega_{g}^{2} / \omega^{2}$ for $\omega>\omega_{g}$ while at $\omega=\omega_{g}$ it becomes $1 / 2 \mathrm{n}$. The differential equation represented by Eqs. (18) and (20) is

$$
\ddot{\theta}+2 \eta_{g} \omega_{g} \dot{\theta}+\omega_{g}^{2} \theta=\frac{T}{\mathrm{~T}} e_{i n}
$$

\section{SEISMOMETER-GALVANOMETER COMBINATION}

Figure 3 shows the electrical schematic of the seismometer-galvanometer combination. In the figure rectangles represent resistors and baw tooth shapes represent the internal resistance of a component. The variable resistor $\left(R_{d}\right)$ is used to control the damping of the seismometer but it, also affects the galvanometer. Across the input terminals to the photo tube amplifier (PTA) is an $80 \Omega$ bridged "T" attenv xtor which is supposed to be loaded with $80 \Omega$ on both sides. This load achieves the attenuation

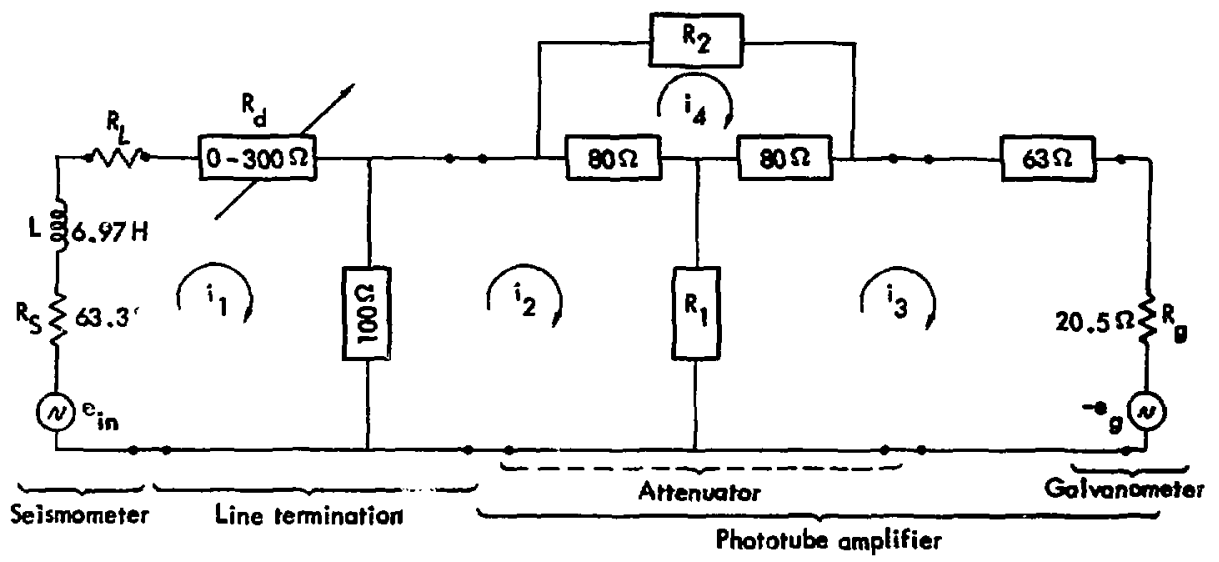

Fig. 3. Electrical schematic of geismometer-galvanometer combination. $R_{1}=80 /(k-1)$, $R_{2}=80(K-1)$, and $K=10(d B / 20)$. $R_{s}$ decotes internal inductance, $L$ is inductance of the coils in the seismometer's transducer, $R_{g}$ is the internal resistance of the galvanometer, and $R_{L}$ is the resistance of the cable. 
indicated on the dial and maintains the same input or output impedance regardless of dial setting. To balance the input of the attenuator requires a value for $x_{d}$ of $337.5 \Omega$ minus line resibtance $\left(\mathrm{R}_{L}\right)$ which for Mina is estimated to be 15 to $20 \Omega$ Any other value for this component means the attenuator is potentially unbalanced to some degree. This, in turn, means that the damping lodd on the galvanometer is not independent of the attenuator setting. For this reason the attenuator has been included in the analysis and the system of coupled equations has been solved. However, as will be seen later, this effect is not significant.

To analyze the system we begin with the equations of motion which are identical to Eqs. (5) and (16) except for the currents

$$
\begin{aligned}
& \text { seismometer: } \overline{\mathbf{x}}\left(-\omega^{2}+2 h_{s} \omega_{s} j \omega+\omega_{s}^{2}\right)+\frac{K_{s}}{M} \bar{i}_{1}=\omega^{2} \bar{z} \\
& \text { galvanometer: } \bar{\theta}\left(-\omega^{2}+2 h_{g} \omega_{g} j \omega+\omega_{g}^{2}\right)=\left(T_{g} / I\right) \bar{i}_{3} .
\end{aligned}
$$

Next the circuit equations are required in order to solve for $\bar{i}_{1}$ and $\bar{i}_{3}$, the currents out of the seismometer and into the galvanometer, respectively. For the loops defined in Fig. 3, the circuit equations are

$$
\begin{aligned}
& K_{s} j \omega \vec{x}=j \omega L \bar{i}_{1}+\left(162.5+R_{d}+R_{L}\right) \bar{i}_{1}-100 \bar{i}_{2} \\
& 0=\left(180+\frac{80}{K-1}\right) \bar{i}_{2}-100 \bar{i}_{1}-\left(\frac{80}{K-1}\right) \bar{i}_{3}-80 \bar{i}_{4} \\
& 0=\left(163.5+\frac{80}{K-1}\right) \bar{i}_{3}+T g j-\left(\frac{80}{K-1}\right) \bar{i}_{2}-80 \bar{i}_{4} \\
& 0=(160+80(k-1)) \bar{i}_{4}-80 \bar{i}_{2}-80 \bar{i}_{3} .
\end{aligned}
$$

where, as before, the bar denotes the Fourier transform and $\mathrm{K}$ is determined by setting the attenuator in $\mathrm{DB}$, as follows

$$
K=10^{(D B / 20)}
$$

Straightforward manipulation of the circuit equations yields the following solutions for $\bar{i}_{3}$ and $\bar{i}_{2}$

$$
\tilde{i}_{3}=\frac{800 \mathrm{Ki},-T_{g} \mathrm{j} \bar{\theta}\left(9 \mathrm{~K}^{2}-1\right)}{1471.5 \mathrm{~K}^{2}-3.5}
$$


and

$$
\overline{\mathrm{i}}_{1}=\left[\mathrm{K}_{\mathrm{s}} \mathrm{j \omega \overline { \textrm {x } }}-\frac{800 \mathrm{KT} \mathrm{g}^{\mathrm{j} \omega \bar{\theta}}}{1471.5 \mathrm{~K}^{2}-3.5}\right] /\left(j \omega \mathrm{L}+\mathrm{R}_{\mathrm{T}}\right),
$$

where

$$
R_{T}=162.5+R_{d}+R_{L}-\frac{500}{\left(9 K^{2}-1\right)}\left[\left(K^{2}-1\right)+\frac{1280 K^{2}}{\left(1471.5 K^{2}-3.5\right)}\right]
$$

The transfer function for the PTA, can now be found by combining Eqs. (29) and (23) so that the ratio of the deflection of the galvanometer to the input current is

$\frac{\theta}{\bar{i}_{1}}=\left[\frac{800 \mathrm{~K}\left(\mathrm{~T}_{\mathrm{g}} / \mathrm{I}\right)}{1471.5 \mathrm{~K}^{2}-3.5}\right] /\left[-\omega^{2}+\mathrm{j} \omega\left(2 \mathrm{~h}_{\mathrm{g}} \omega_{\mathrm{g}}+\frac{\left(\mathrm{T}_{\mathrm{g}}^{2} / \mathrm{I}\right)\left(9 \mathrm{~K}^{2}-1\right)}{1471.5 \mathrm{~K}^{2}-3.5}\right)+\omega_{g}^{2}\right]$.

The damping term,

$$
\eta_{g}=h_{g}+\frac{\left(T_{g}^{2} / I\right)\left(9 K^{2}-i\right)}{2\left(1471.5 K^{2}-3.5\right) \omega_{g}}
$$

is seen to be a function of the attenuator satting.

The magnification for the seismometer is found by combining Egs. (22) and (32) with Eq. (30) and solving for $\bar{i}_{1}$, the output current,

$$
\frac{\bar{i}_{1}}{\bar{z}}=\frac{K_{s} j \omega^{3}}{\left(R_{T}+j \omega L\right)\left(\omega_{s}^{2}-\omega^{2}+2 h_{s} \omega_{s} j \omega\right)+j \omega\left[\frac{K_{s}^{2}}{M}+C_{0}^{2}\left(\frac{T_{g}^{2}}{T}\right)\left(\frac{\omega_{s}^{2}-\omega^{2}+2 h_{s}{ }_{s}^{j}{ }^{j \omega}}{\omega_{g}^{2}-\omega^{2}+2 n_{g} \omega_{g} j \omega}\right)\right]},
$$

where

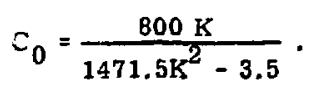

If the inductance $I$ could be neglected the damping of the system would be governed by the coefficient of $\mathrm{j} \omega$, namely,

$$
\frac{\kappa_{\mathrm{g}}^{2}}{M}+c_{0}^{2}\left(\frac{T_{g}^{2}}{T}\right)\left[\frac{\omega_{g}^{2}-\omega^{2}+2 h_{s} \omega_{s} j \omega}{\omega_{g}^{2}-\omega^{2}+2 \eta_{g} \omega_{g}^{j} j \omega}\right]
$$


which is a function of not only the load on the seismometer resulting from the magnetic field and coils but also of the load due to the galvanometer magnetic field. The extent to which this is important is determined by the attenuator. It turns out, as can be shown from Eq. (35), that this is a noticeable effect for an attenuator setting of less than about $18 \mathrm{~dB}$.

The overall magnification for the seismometer-galvanometer combination is the product of Eqs. (32) and (33).

$$
\begin{array}{r}
\frac{\bar{\theta}}{\bar{z}}=C_{0}\left(T_{g} / L\right) K_{s} j \omega^{3} /\left(R_{T}+j \omega L\right)\left(\omega_{g}^{2}-\omega^{2}+2 h_{s} \omega_{s}^{j \omega}\right)\left(\omega_{g}^{2}-\omega^{2}+j \omega 2 \eta_{g} \omega_{g}\right) \\
+j \omega\left[\frac{K_{s}^{2}}{M}\left(\omega_{g}^{2}-\omega^{2}+j \omega 2 \eta_{g} \omega_{g}\right)+C_{0}^{2}\left(\frac{T_{g}^{2}}{I}\right)\left(\omega_{g}^{2}-\omega^{2}+2 h_{s} \omega_{s} j \omega\right)\right] .
\end{array}
$$

The fifth order differential equation represented by Eq. (36) can be found by carrying out the term-by-term and cross multiplications as indicated by the equation and by reversing the transformation. That is, $j \omega \bar{\theta}$ becomes (as it was originally) simply $\mathrm{d} \theta / \mathrm{dt}$ and $-\omega^{2} \bar{\theta}$ becomes $\mathrm{d}^{2} \theta / \mathrm{dt}^{2}$ and so on. The result is

$L \frac{d^{5} \theta}{d t^{5}}+A_{4} \frac{d^{4} \theta}{d t^{4}}+A_{3} \frac{d^{3} \theta}{d t^{3}}+A_{2} \frac{d^{2} \theta}{d t^{2}}+A_{1} \frac{d \theta}{d t}+\omega_{S}^{2} \omega_{E}^{2} \theta=-C_{0}\left(\frac{T}{T}\right) K_{s} \frac{d^{3} z}{d t^{3}}$,

where

$A_{4}=\mathbf{R}_{\mathrm{T}}+\mathbf{L}\left(2 h_{\mathrm{s}} \omega_{\mathrm{s}}+2 \eta_{\mathrm{g}} \omega_{\mathrm{g}}\right)$

$A_{3}=R_{T}\left(2 h_{s} \omega_{s}+2 h_{g} \omega_{g}\right)+L\left(\omega_{s}^{2}+4 h_{g} \eta_{g} \omega_{s} \omega_{g}+\omega_{g}^{2}\right)+\frac{K_{s}^{2}}{M}+C_{0}^{2}\left(T_{g}^{2} / I\right)$,

$A_{2}=R_{T}\left(\omega_{s}^{2}+4 h_{s} \eta_{g} \omega_{s} \omega_{g}+\omega_{g}^{2}\right)+L\left(2 \eta_{g} \omega_{g} \omega_{s}^{2}+2 h_{s} \omega_{s} \omega_{g}^{2}\right)+\frac{K_{s}^{2}}{M} 2 \eta_{g} \omega_{g}+C_{0}^{2}\left(\begin{array}{l}T_{g}^{2} \\ T^{2}\end{array}\right) 2 h_{s} \omega_{s}$,

and

$A_{1}=I \omega_{s}^{2} \omega_{g}^{2}+R_{T}\left(2 \eta_{g} \omega_{g} \omega_{S}^{2}+2 h_{s} \omega_{s} \omega_{g}^{2}\right)+\frac{K_{g}^{2}}{M} \omega_{g}^{2}+C_{0}^{2}\left(\frac{T_{g}^{2}}{T}\right) \omega_{S}^{2}$.

\section{PTA FILTER}

The filter in the PTA is described in the Geotech Operation and Maintenance Manual as a band pass filter with $6 \mathrm{~dB} /$ oct attenuation on the low frequency side and $12 \mathrm{~dB} /$ oct on the high side. A model for this filter can be obtained by combining 
a first order differential equation, which simulates the high pass side, with a second order differential equation, which simulates the low pass side. This is achieved with the following equations

$$
\begin{aligned}
& \text { First order: } \dot{e}_{1}+\omega_{1} e_{1}=\dot{e}_{0} \\
& \text { Second order: } \ddot{e}_{2}+2 \eta \omega_{2} \dot{e}_{2}+\omega_{2}^{2} e_{2}=w_{2}^{2} e_{1},
\end{aligned}
$$

where $e_{0}$ is the input voltage to the high pass portion, $e_{1}$ is the corresponding output and also the input to the low pass section, $\omega_{1}$ and $\omega_{2}$ are the circular frequencies at which the amplitude responses are down $3 \mathrm{~dB}$, when $\eta=\sqrt{2} / 2$.

That Eqs. (38) and (39) have the desired frequency response can be shown by taking the Fourier transforms of each of them and solving for the ratio of the output to the input. Carrying out these operations results in the following expression for the first and second order equations, respectively.

$$
\begin{gathered}
\frac{\bar{e}_{1}}{\bar{e}_{0}}=\frac{j \omega}{j \omega+\omega_{1}} \text { or }\left|\frac{\bar{e}_{1}}{\bar{e}_{0}}\right|=\frac{\omega}{\left[\omega^{2}+\omega_{1}^{2}\right]^{1 / 2}} \\
\frac{\bar{e}_{2}}{\bar{e}_{1}}=\frac{\omega_{2}^{2}}{\omega_{2}^{2}-\omega^{2}+2 \eta \omega_{2} i \omega} \quad \text { or }\left|\frac{\bar{e}_{2}}{\bar{e}_{1}}\right|=\frac{\omega_{2}^{2}}{\left[\left(\omega_{2}^{2}-\omega^{2}\right)^{2}+4 \eta^{2} \omega_{2}^{2} \omega^{2}\right]^{1 / 2}}
\end{gathered}
$$

Equation (40) shows that the response apprnaches unity for $\omega>\omega_{1}$ while the respanse decreases linearly with decreasing frequency for $\omega<\omega_{1}$. Similarly, Eq. (41) shows that the response approaches unity for $\omega<\omega_{2}$ and that it decreases with increasing frequency to the second power for $\omega>\omega_{2}$. Both of these are desired frequency responses and it remains only to specify $\omega_{1}$ and $\omega_{2}$.

The complete model for the filter is obtained by combining Eqs. (40) and (41) to get a single expression for the output in terms of the input

$$
\bar{e}_{2}=\frac{j \omega \omega_{2}^{2} \bar{e}_{0}}{\left(j \omega+\omega_{1}\right)\left(\omega_{2}^{2}-\omega^{2}+2 \eta \omega_{2} j \omega\right)} .
$$

If the denominator of $\mathrm{Eq} .(42)$ is removed by cross multiplication and all other multiplications carried out as well, it can be rewritten as a third order differential equation

$$
\ddot{\mathrm{e}}_{2}+\left(2 \eta \omega_{2}+\omega_{1}\right) \ddot{\mathrm{e}}_{2}+\left(\omega_{2}^{2}+2 \eta \omega_{2} \omega_{1}\right) \dot{\mathrm{e}}_{2}+\omega_{1} \omega_{2}^{2} \mathrm{e}_{2}=\omega_{2}^{2} \dot{\mathrm{e}}_{0} \text {. }
$$


Of the four frequency sensitive items (seismometer, PTA galvanometer, PTA band-pass filter, and film recorder galvanometer), only the seismometer and PTA Galvanometer interact with each other and this is only appreciable when the attenuator is set at a low value. The PTA galvanometer is isolated from the PTA fii.er by the light source and photo-cell arrangement while the PTA filter is in turn decoupled from the film recorder galvanometer by a signal isolation transformer. Consequently, the deflection of the PTA galvanometer is scaled by a constant to convert angular deflection into volts. This deflection becomes the input to the PTA filter, whose output, in turn, becomes the input to the film recorder galvanometer. The ultimate outcome is, of course, a trace on $35-\mathrm{mm}$ film with an amplitude proportional to the angular deflection, $\theta_{f}$, of the film recorder galvanometer. To summarize, the entire system can then be described by the following differential equat: .48 .

(a) Equation (37)

$L \frac{d^{5} \theta}{d t^{5}}+A_{4} \frac{d^{4} \theta}{d t^{4}}+A_{3} \frac{d^{3} \theta}{d t^{3}}+A_{2} \frac{d^{2} \theta}{d t^{2}}+A_{1} \frac{d \theta}{d t}+\omega_{s}^{2} \omega_{g}^{2} \theta g=C_{0}\left(\frac{T g}{I}\right) K_{s} \frac{d^{2} v}{d t^{2}}$,

where ground velocity (v) has replaced ground displacement $(z)$.

(b) Equation (43)

$\frac{d^{3} e}{d t^{3}}+\left(2 \eta \omega_{2}+\omega_{1}\right) \frac{d^{2} e}{d t^{2}}+\left(\omega_{2}^{2}+2 \eta \omega_{2} \omega_{1}\right) \frac{d e}{d t}+\omega_{1} \omega_{2}^{2} e=\omega_{2}^{2} c_{1} \frac{d g}{d t}$

where $e$ is the voltage output of the filter, and $C_{1}$ : : a constant which coni*; rts the angular displacement of the PTA galvanometer into volts at the input to the PTA filter.

(c) Equation (21)

$$
\frac{d^{2} \theta_{f}}{d t^{2}}+2 \eta_{f} \omega_{f} \frac{d \theta_{f}}{d t}+\omega_{f}^{2} \theta_{f}=\frac{T_{f}}{I_{f}} C_{2} e
$$

where $\theta_{\mathrm{f}}$ is the angular deflection of the film recorder galvanometer, and $\mathrm{C}_{2}$ is a constant to scale the amplitude of the PTA filter output to the input of the film recorder galvanometer.

The three above equations have been solved numerically by approximating the derivatives with backward differences such as 


$$
\frac{d \theta_{g}}{d t} \approx \frac{\theta_{g}(n)-\theta_{g}(n-1)}{\Delta t}
$$

where $n$ replaces the continuous variable time, $t$, bur is related to it by

$$
t=n \Delta t
$$

where

$$
\mathrm{n}=0,1,2, \ldots
$$

and $\Delta t$ is the time increment between samples. The results, afier collecting terms and solving for the present values, are

a) $\begin{aligned} \theta_{g}(n)= & \left\{-(\Delta t)^{3} C_{0} T_{I}^{T} K_{g}[V(n)-2 V(n-1)+V(n-2)]+B_{I} \theta_{g}(n-1)\right. \\ & \left.-B_{2} \theta_{g}(n-2)+B_{3} \theta_{g}(n-3)-B_{4} \theta_{g}(n-4)+L \theta_{g}(n-5)\right\} / B_{0^{*}}\end{aligned}$

where

$$
\begin{aligned}
& B_{0}=L+A_{4}(\Delta t)+A_{3}(\Delta t)^{2}+A_{2}(\Delta t)^{3}+A_{1}(\Delta t)^{4}+\omega_{s}^{2} \omega_{g}^{2}(\Delta t)^{5} \\
& B_{1}=5 L+4 A_{4}(\Delta t)+3 A_{3}(\Delta t)^{2}+2 A_{2}(\Delta t)^{3}+A_{1}(\Delta t)^{4} \\
& B_{2}=10 L+6 A_{4}(\Delta t)+3 A_{3}(\Delta t)^{2}+A_{2}(\Delta t)^{3} \\
& B_{3}=10 L+4 A_{4}(\Delta t)+A_{3}(\Delta t)^{2} \\
& B_{4}=5 L+A_{4}(\Delta t)
\end{aligned}
$$

and

$$
\theta_{\mathrm{g}}(-1)=\theta_{\mathrm{g}}(-2)=\theta_{\mathrm{g}}(-3)=\theta_{\mathrm{g}}(-4)=\theta_{\mathrm{g}}(-5)=\mathrm{V}(-1)=\mathrm{V}(-1)=\mathrm{V}(-2)=0
$$

b) $\quad e(n)=\left\{\omega_{2}^{2}(\Delta t)^{2} C_{1}\left[\theta_{g}(n)-\theta_{g}(n-1)\right]+D_{1} e^{(n-1)}-D_{2} e^{(n-2)+e(n-2)}\right\} / D_{0^{\prime}}$

where

$$
D_{0}=1+\left(2 \eta \omega_{2}+\omega_{1}\right)(\Delta t)+\left(\omega_{2}^{2}+2 \eta \omega_{2} \omega_{1}\right)(\Delta t)^{2}+\omega_{1} \omega_{2}^{2}(\Delta t)^{3}
$$




$$
\begin{aligned}
& D_{1}=3+2\left(2 \eta \omega_{2}+\omega_{1}\right)(\Delta t)+\left(\omega_{2}^{2}+2 \eta \omega_{2} \omega_{1}\right)(\Delta t)^{2} \\
& D_{2}=3+\left(2 \eta \omega_{2}+\omega_{1}\right)(\Delta t)
\end{aligned}
$$

and

$$
e(-1)=e(-2)=3(-3)=0 \text {. }
$$

c) $\quad \theta_{f}(n)=\left(T_{f} / I\right) C_{2}\left\{e(n)+E_{1} \theta_{f}(n-1)-\theta_{f}(n-2)\right\} / E_{0}$,

where

$$
\begin{aligned}
& E_{0}=1+2 \eta_{f} \omega_{f}(\Delta t)+w_{f}^{2}(\Delta t)^{2} \\
& E_{1}=2\left(1+\eta_{f} \omega_{f}(\Delta t)\right)
\end{aligned}
$$

and

$$
\theta_{\mathrm{f}}(-1)=\theta_{\mathrm{f}}(-2)=0
$$

Equations (49), (50), and (51) are known as recursive because past values of the solution are us $i$ to calculate the present value. The input is thought to be ground velocity because the transducer is basically sensitive to velocity and because the system which replaced the Benioff system has a flat response to velocity over the entire passband of the Benioff system.

A code has been written which makes the above calculations; numerical results are discussed in another section of this document. A listing of the code is given in the Appendix.

\section{Measurement of Parameters}

\section{SEISMOMETER}

\section{Transducer Internal Resistance and Inductance}

To measure the internal resistance $\left(R_{s}\right)$ of the transducer, we bolted the mass of the seismometer in the center position to eliminate earth noise-generated currents in the tranaducer. Thus, we eliminated the contribution of the inductance to the impedance measurement. The value read at the seismometer terminals on a five place digit voltmeter was 


$$
R_{s}=63.3 \Omega
$$

We also measured the inductance while the mass was locked into the center position. This measurement was made using a function generitor to drive the transducer in series with a known resistor and at a known frequency. The voltages across the transducer terminais and across the known resistor were recorded on a high impedance strip chart recorder. The ratio of the peak-to-peak amplitudes were then used to solve for the inductance. Eight frequencies from 1 to $20 \mathrm{~Hz}$ were used with a sample mean and standard deviation of

$$
\mathbf{L}=6.97 \pm 0.06 \mathrm{H} \text {. }
$$

\section{Natural Damping and Free Period}

Natural damping is the amount of damping present and free period is the length of time during which the instrument will vibrate when perturbed under either zero or negligible electrical load. Natural frequency, the reciprocal of free period, can be created by switching in the $200-\mathrm{k} \Omega$ resistor in the line termination module (Fig. 2) and then applying a momentary force with either the ball lift or electro-magnetic calibrators. The normal resistive load $(R)$ is on the order of $160 \Omega$. Thus, $E y$. (6) shows that increasing $R$ to over $200 \mathrm{k} \Omega$ clearly reduces the inductive term to insignificance.

Since this test was routinely made by the Geotech personnel following every NTS event, abundant information is available to evaluate this parameter. We selected one of these tests and microscopically examined the peak-to-peak amplitudes. The same test was performed in the laboratory after the system had been reassembled. Figidre 4 shows the results of both tests; note that the rate of decay had not changed.

The following equation was used to compute the natural damping

$$
\log _{e} \frac{A_{i}}{A_{i+1}}=\frac{2 \pi h}{\sqrt{1-h^{2}}}
$$

where $A_{i}$ is the peak-to-peak amplitude. An average value of the natural log of the ratio of $A_{i}$ to $A_{i+1}$ was found from the slope of the data of Fig. 3 and this value was used in Eq. (52) to calculate

$$
h=0.0096
$$

However, the free period was not the same as in the field. As will be shown later, considerable variation existed in the free period from one test to the next. 


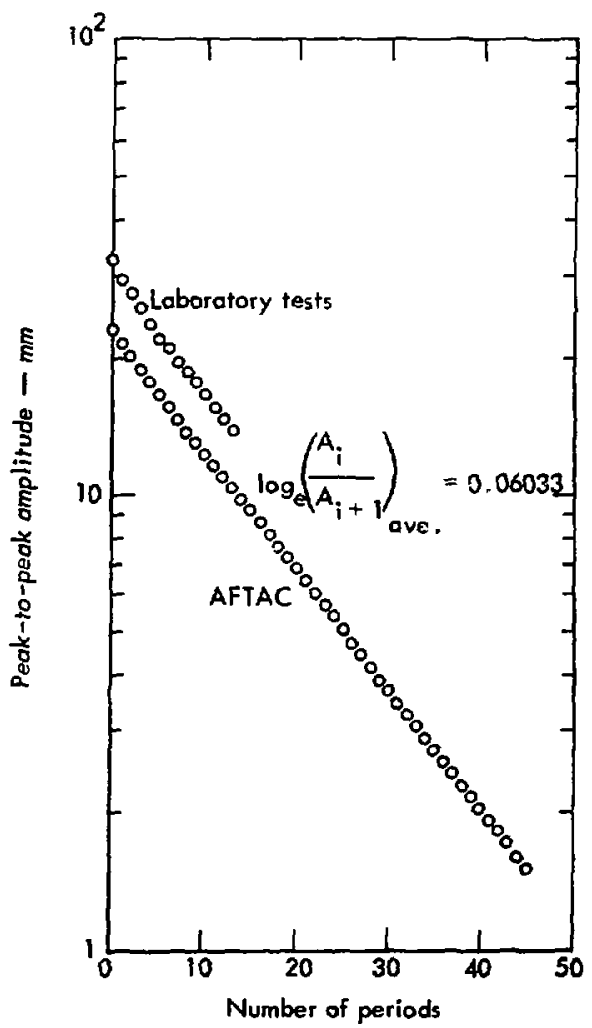

Fig. 4. Benioff natural damping teat.
The free period averaged over 60 cycles in the lab and during the shake table test. This yielded an undamped period of

$$
T^{*}=1.0693 \mathrm{sec} \text {, }
$$

where $T$ is the undamped period and the prime is the observed period. The two periods are related by

$$
T=\sqrt{1-h^{2}} T^{\prime} .
$$

However, since $h$ is go small, the observed and true periods are nearly identical.

\section{Transducer Generator Constant}

To determine the generator constant we performed static and dynamic tests and found that the results agreed to withir $4 \%$.

\section{Static Test}

The static test is simpler and consists of placing a small known weight on the mass of the seismometer and then applying a constant current to the transducer to drive the mass back to its original position. At this point the force acting in the transducer should equal the force of the weight so that the generator constant can be computed from

$$
K_{B}=\frac{9.8 \mathrm{~m}}{\mathbf{I}} \text {. }
$$

where 9.8 is the gravitational constant, $m$ is the mass in $\mathrm{kg}$ of the test weight and $\mathrm{I}$ is the constant current.

The chief difficulty in performing this test is the problem of determining when the mass has been returned to its original position. If the test weight is $250 \mathrm{~g}$ and the effective spring constant is $3.71 \mathrm{n} / \mathrm{mm}$, then the mass must be returned to within $0.033 \mathrm{~mm}$ of its initial position for the results to be accurate within $5 \%$. To accomplish \#Computed from $\omega_{B}=5.8751 / \mathrm{sec}$ and $M=107.5 \mathrm{~kg}$. 
this a non-contacting displacement gage, made by the Bentley Corporation of Nevada," was borrowed from the transducer lab. It was mounted to the frame of the seismometer so that its output was proportional to the relative displacement between the frame and the mass. The sensitivity of the gage was $20.11 \mathrm{~V} / \mathrm{mm}$ so that the $5 \%$ figure could be easily attained, since a displacement of $0.033 \mathrm{~mm}$ would produce a voltage of $0.664 \mathrm{~V}$ which is easily recorded.

Figure 5 shows the results of the tests. The testing procedure was to first record the output of the Ben1ley gage and then to apply weight. Next, a constant current was applied to the transducer and we recorded current readings at several levels and the corresponding Bentley output. Finally, after removing the current and the test weight, the output of the Bentley gage was noted. The zero load and zero current reading of the Bentley before and after the test differed by $40 \mathrm{mV}$ or approximately $0.002 \mathrm{~mm}$. Thus, the force resulting from spring rate amounts to approximately $0.3 \%$ of the test weight. However, the corresponding uncertainty in the current is approximately $1 \%$ (Fig. 5), and this results in a generator constant in N/A of

$365 \leq \mathrm{K}_{\mathrm{s}} \leq 369$.

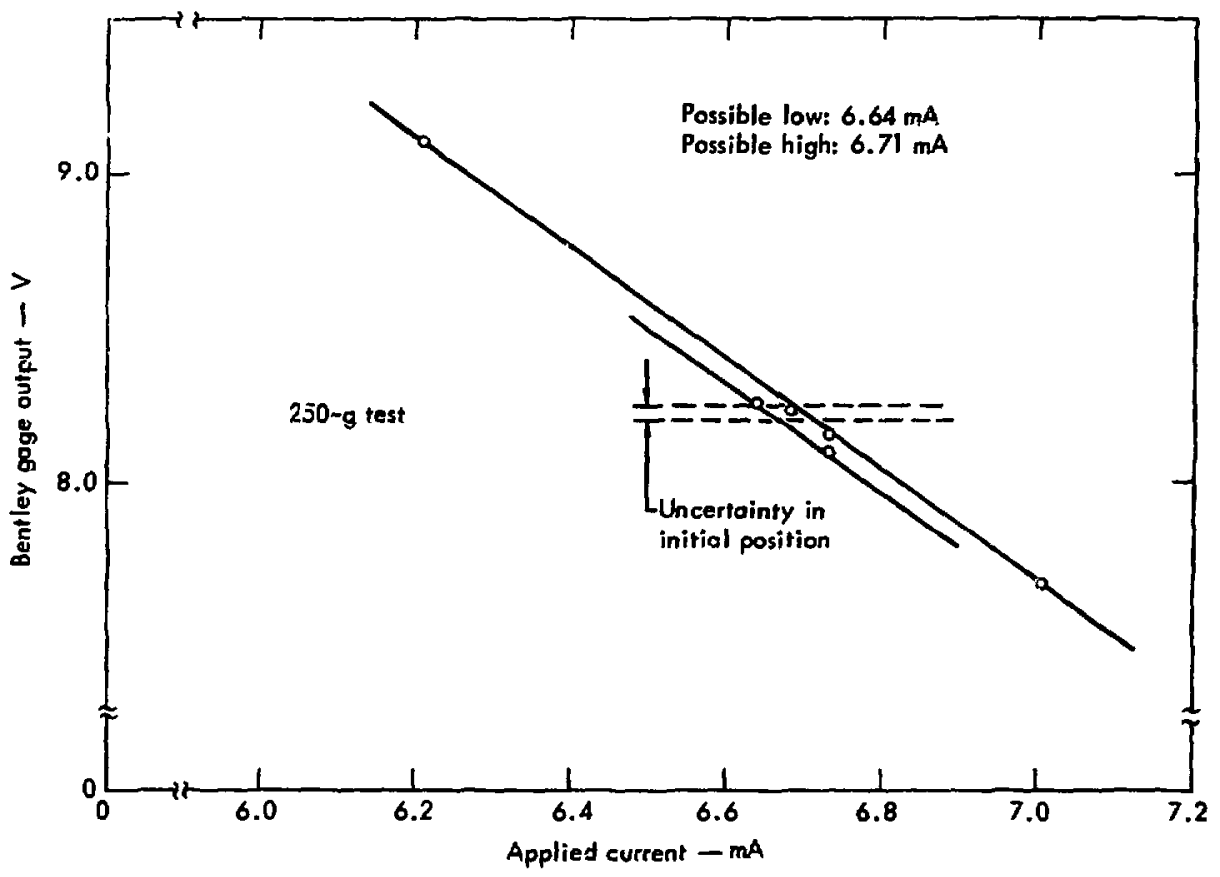

Fig. 5. Weight lift test.

Reference to a company or product name does not imply approval or recommendation of the product by the University of California or the U.S. Atomic Energy Commission to the exclusion of others that may be suitable. 


\section{Dynamic Test}

The purpose of this test was to obtain an experimental magnification plot from which, with the aid of Eq. (13), the generator constant $\left(\mathrm{K}_{\mathrm{s}}\right)$ and also the motor constant of the calibration coil can be determined. To meet this objective the test was run at 14 frequencies ranging from 0.1 to $30 \mathrm{kz}$ and at four levels of displacement. The displacement levels were nominally $0.254,0.508,1.016$, and $1.27 \mathrm{~mm}$ peak-topeak. Useful data were obtained on 49 of the 64 runs. The displacement of the seismometer base was monitored by a linear voltage displacement transformer (LVDT). The outputs of the LVDT and the seismometer's transducer were recorded on magnetic tape. The output of the transducer was terminated into a $79.7-\Omega$ resistor.

Using the LVDT, we measured the ratio of transducer voitage output to displacement. This ratio is called experimental magnification, and is in units $\mathrm{mV} / \mathrm{mm}$. Many records contained enough noise to make measurement of the peak-to-peak amplitudes unreliable. Consequently, data from the LVDT and the transducer were digitized over identical segments of time and transformed into the frequency domain through the use of the fast Fourier transform algorithm. The resultant transform, in general, showed a large peak value at the frequency of the test. The ratio of these peak values was used to obtain the magnification values given in Table 1.

Table 1 also gives an indication of the linearity of the seismometer. Note that 3 readings of the magnification at $0.2 \mathrm{~Hz}$ have a deviation of approximately $1 / 2 \%$ but at $10 \mathrm{~Hz}$ three readings have a deviation of $7.5 \%$, while the mean deviation for 11 irequencies is $3.4 \%$. These data do not show any nonlinearity because there is no $\rightarrow$ r.parent trend, that is, data from the highest test level are neither consistently high nur low.

The generator constant values given in Table 1 were found by evaluating Eq. (13) and by plotting the magnif sation against the generator constant for each of the test frequencies. The generator constant for each experimental value of magnification was then read directly from these plots. The sample mean and standard deviation for the thirteen values in Table 1 are

$$
K_{\mathrm{g}}=355.2 \pm 11.8 \mathrm{n} / \mathrm{A} \text {. }
$$

To evaluate Eq. (13) we wrote code using the following constants

$$
\begin{aligned}
\omega_{s} & =2 \pi(0.9355)=5.878 \mathrm{r} / \mathrm{sec}^{\dagger} \\
h_{S} & =0.0096 \\
L & =6.97 \mathrm{H} \\
R & =143 \Omega \\
M & =107.5 \mathrm{~kg} \\
S & =79.7 \Omega
\end{aligned}
$$

\footnotetext{
Not included in this document.

The natural frequency as it existed at the time of the test.
} 
Table 1. Magnification and deduced generator constant magnification $\frac{\mathrm{mv}}{\mathrm{mm}}$.

\begin{tabular}{|c|c|c|c|c|c|c|}
\hline \multirow[b]{2}{*}{ Frequency } & \multicolumn{4}{|c|}{ Run } & \multirow[b]{2}{*}{ Mean } & \multirow{2}{*}{$\begin{array}{c}\text { Generator } \\
\text { constant } K_{s} \\
\text { (n/A) }\end{array}$} \\
\hline & $0.254 \mathrm{~mm}$ & $0.508 \mathrm{~mm}$ & $1.016 \mathrm{~mm}$ & $1.27 \mathrm{~mm}$ & & \\
\hline 0.2 & - & 11.057 & 11.146 & 11.000 & $11.068 \pm 0.54 \%$ & 353 \\
\hline 0.5 & - & 156.24 & 159.22 & 159.59 & $158.02 \pm 0.8 \%$ & 366 \\
\hline 0.8 & 554.26 & 553.78 & 545.98 & 577.29 & $559.2 \pm 2.11 \%$ & 354 \\
\hline 1.0 & 952.84 & - & 914.08 & 967.37 & $944.7 \pm 2.38 \%$ & 361 \\
\hline 1.2 & 1502.7 & 1439.9 & 1355.7 & - & $1432.8 \pm 4.2 \%$ & 355 \\
\hline 1.5 & 2177.1 & 2142.1 & 1946.4 & 2019.1 & $2071.2 \pm 4.49 \%$ & 386 \\
\hline 2.0 & $3219 .:$ & 3100.7 & 2863.5 & 2978.2 & $3040.4 \pm 4.37 \%$ & 349 \\
\hline 2.5 & 3753.7 & 3480.1 & 3301.1 & - & $3511.6 \pm 5.3 \%$ & 351 \\
\hline 3.0 & 4052.3 & 3756.81 & 3827.4 & - & $3878.8 \pm 3.25 \%$ & 362 \\
\hline 5.0 & 3956.6 & 3962.9 & 3762.5 & 3920.9 & $3900.7 \pm 2.1 \%$ & 348 \\
\hline 10.0 & - & 3918.3 & 3678.9 & 4400.0 & $3999.0 \pm 7.5 \%$ & 352 \\
\hline 20.0 & 3872.8 & 4085.3 & - & - & 3979.0 & 348 \\
\hline 30.0 & 3767.0 & 3839.0 & - & - & 3803.0 & 333 \\
\hline
\end{tabular}

The following confidence intervals result from using the Student " $t$ " distrilsution:

$\begin{array}{cc}\begin{array}{c}\text { Confi.dence } \\ \text { coefficient }\end{array} & \begin{array}{c}\text { Interval on mean } \\ \text { generator constant }\end{array} \\ 90 \% & 349-361 \\ 95 \% & 347.8-362.6 \\ 99 \% & 346.1-364.3\end{array}$

The estimated population standard deviations using the Chi-Squared distribution are

$\begin{array}{cc}\begin{array}{c}\text { Confidence } \\ \text { coefficient }\end{array} & \begin{array}{c}\text { Interval on standard } \\ \text { deviation }\end{array} \\ 90 \% & 8.9-17.9 \\ 96 \% & 8.3-20.0 \\ 98 \% & 8.0-21.8\end{array}$

Note that the above results of the weight lift test and the shake table test are in agreement within experimental error.

Figure 6 shows the experimental magnification values and the theoretical curve for $\mathrm{K}_{\mathrm{s}}=355 \mathrm{n} / \mathrm{A}$.

\section{Calibration Coil Motor Constant}

Static and dynamic tests were made to determine the wotor constant (G) of the calii ation coil. The results are in agreement to within $6 \%$. 


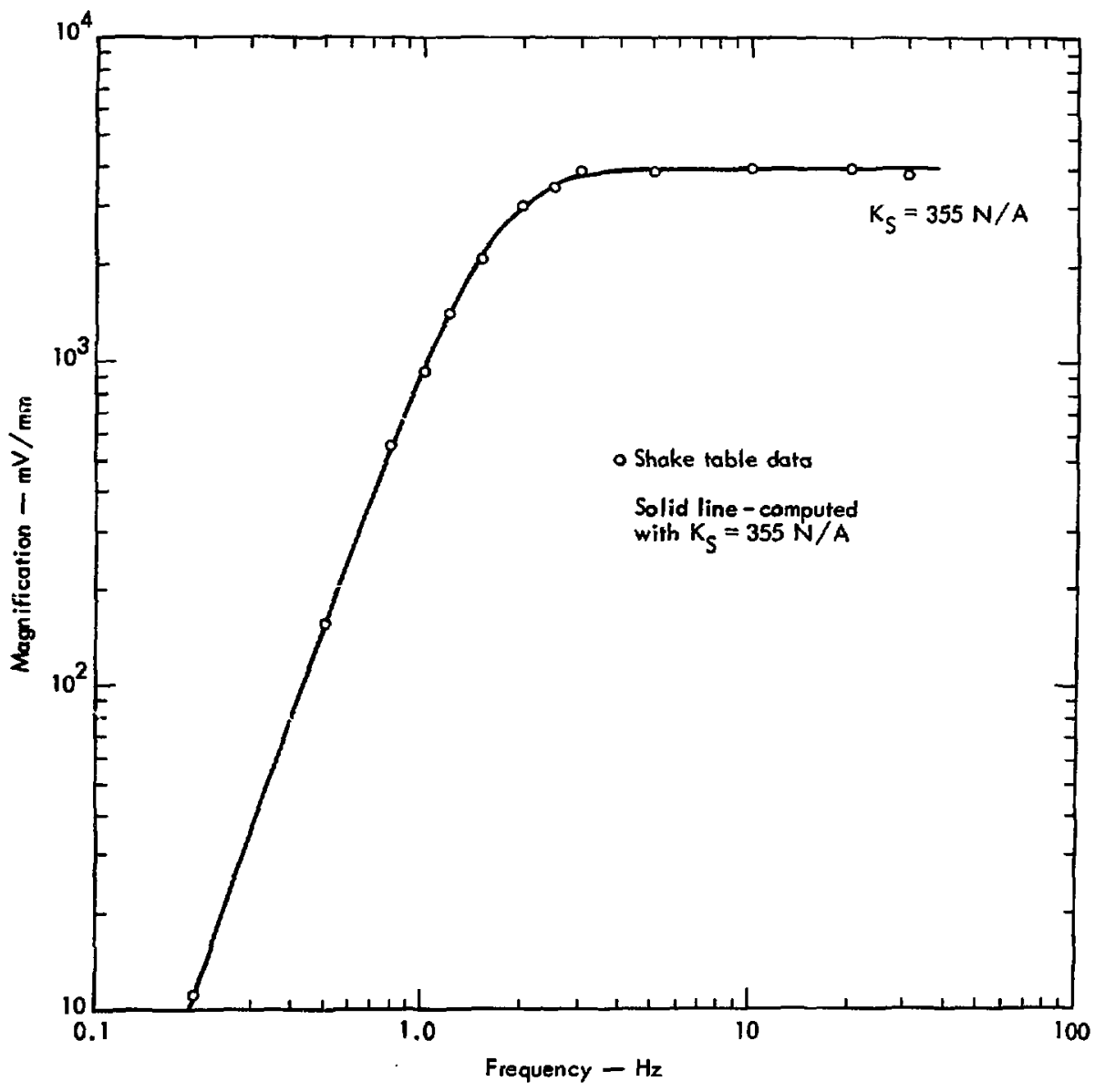

Fig. 6. Magnification determined from shake table data. 
Static Test

In this case, the accuracy of the weight lift test suffered because of both the low strength of the coil itself and the limitations on the maxil um current which could be applied. Figure 7 shows the results of the weight lift test. The error bar is intended

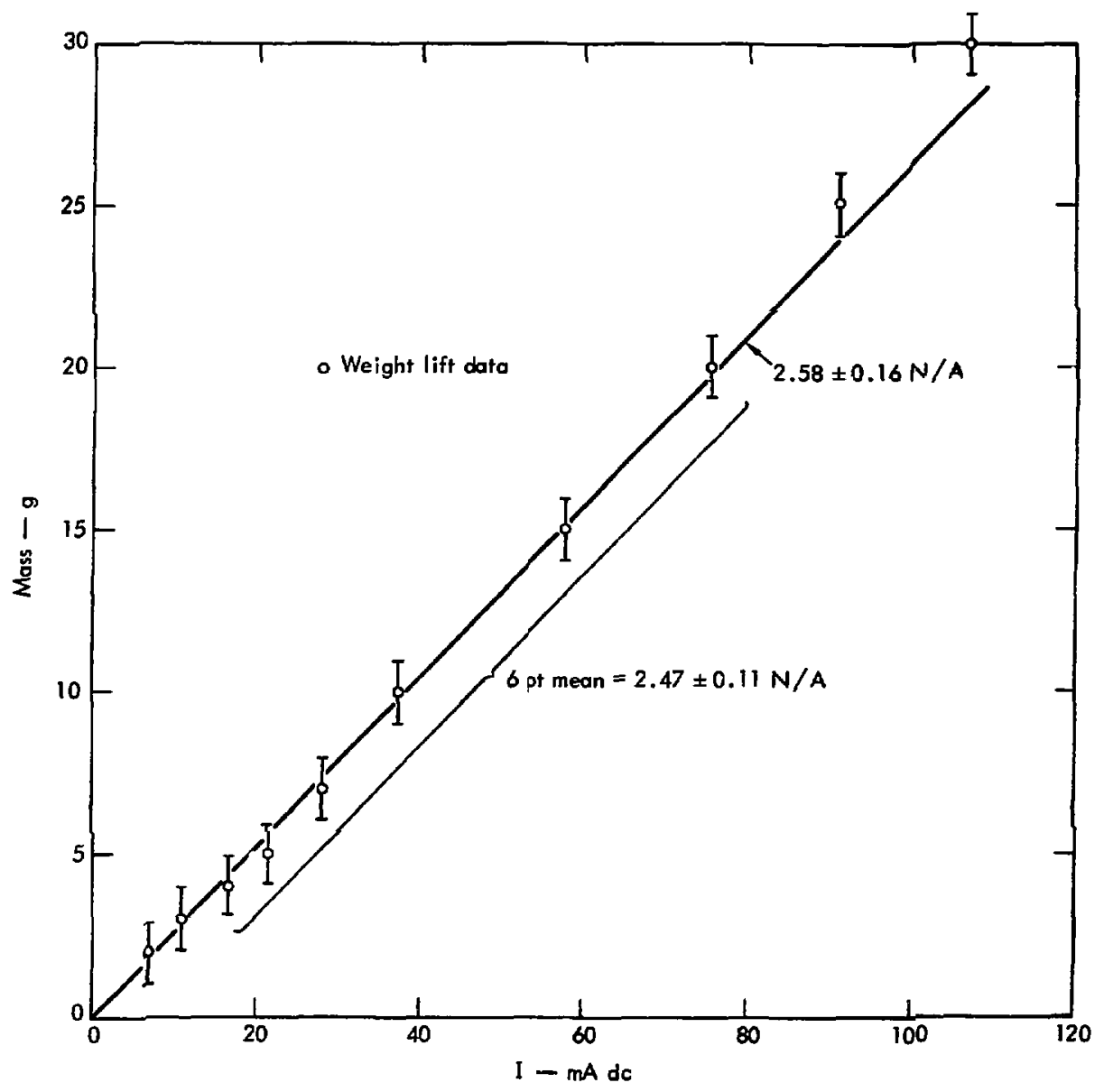

Fig. 7. Weight lift test to determine calibrated coil motor constant. 
to show the uncertainty involved in returning the mass to its initial unloaded position. The mean value and standard deviation for the test sample are

$$
\mathrm{G}=2.58 \pm 0.16 \mathrm{n} / \mathrm{A} \text {. }
$$

The largest calibration ever used in the field to calibrate the system was a $14 \mathrm{~mA}$ peak-to-peak sine wave, equivalent in power to approximately $5 \mathrm{~mA}$ dc. Because of the cultural noise level in the lab, the power levels used (Fig. 7) all exceeded the largest value used in the field. An acceptable current based on the size of the wire used in the calibration coil was calculated to be approximately $55 \mathrm{mAdc}$. This fact raised speculation about the linearity of the device at such high levels, and indeed, Fig. 6 does appear to show a nonlinear trend. To resolve this question, we ran a test to obtain the output of the data coils as a function of the input to the calibration coil. For this tegt a frequency of $1.4 \mathrm{~Hz}$ was used as this is the approximate value of input at which the output is maximum. The results are plotted in Fig. 8 and show that the calibration coil is linear at least up to $115 \mathrm{~mA}$ peak-to-peak ac, with a mean slope of

$$
\mathrm{E} / \mathrm{I}=0.558 \pm 0.015 \mathrm{mV} / \mathrm{mA} \text {. }
$$

Consequently, the apparent nonlinear trend in the weight lift test data is not credible, at least up to $81 \mathrm{~mA} \mathrm{dc}$. If the two values above this level are eliminated from the

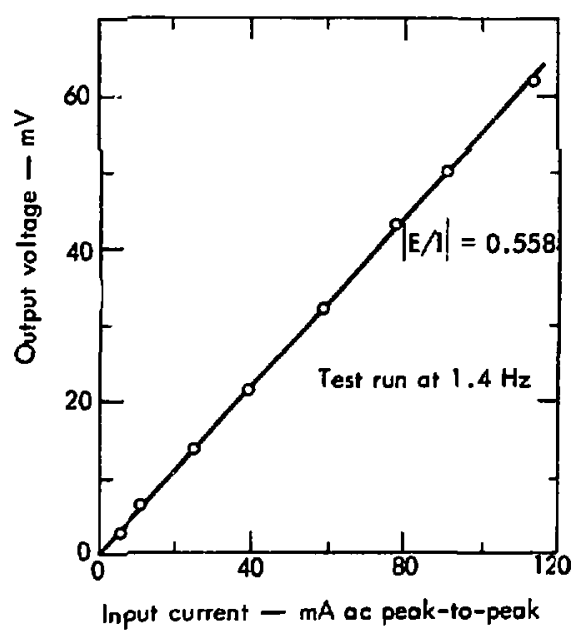

Fig. 8. Calibrated coil linearity. sample (as possibly beyond the linear range) and if the two lowest ones are also eliminated, simply because of the uncertainty resulting from the size of the test weight involved, then the sample mean and standard deviation are

$$
\mathrm{G}=2.47 \pm 0.11 \mathrm{n} / \mathrm{A} \text {. }
$$

\section{Dynamic Test}

The motor constant can be found from the dynamic test by equating the magnification from the shake table data with that found by using the calibration coil. The magnificaticn is determined using the calibration coil by replacing the inertial force on the mass with an equiv alent force produced by the calibration coil, driven with current, $I$, that is, 


$$
\text { - } M \ddot{z}=\text { GI, }
$$

which when transformed is

$$
\overline{\mathrm{z}}=\mathrm{G} \overline{\mathrm{I}} / \mathrm{M} \omega^{2} \text {. }
$$

By substituting Eq. (56) into Eq. (10), the magnification determined by the calibration coil is then

$$
M=\left|\frac{S \bar{i}}{\bar{z}}\right|=\frac{M \omega^{2}}{G}\left|\frac{\bar{E}}{\bar{I}}\right|,
$$

where $\overline{\mathrm{E}}=\mathrm{Si}$ is the voltage across the external damping resistance. The motor constant is now found by equating Eq. (57) to the experimental shake table data $M_{\text {exp' }}$ that is

$$
\mathrm{G}=\frac{\mathrm{M} \omega^{2}|\overline{\mathrm{E}} / \overline{\mathrm{I}}|}{\mathrm{M}_{\mathrm{exp}}} .
$$

Table 2 lists the results of a test in which we measured current in the calibration coil and the corresponding voltage across the external damping resistance (same as the one used during the shake table test). (See Fig. 9.) These values were then used in Eq. (58) to calculate the motor constant, G.

The mean value and standard deviation of the values of $G$ given in Table 2 are

$$
G=2.42 \pm 0.18 \mathrm{~N} / \mathrm{A} \text {. }
$$

Table 3 lists the confidence intervals for the three cases discussed. Note that although the dynamic test has the largest standard deviation it has the smallest confidence interval for a given confidence coefficient because of the larger sample size. For this reason the results of the dynamic test are preferred over the weight lift.

\section{Ball Lift Matching Test}

A third kind of test was employed by the Geotech personnel to determine the calibration coil motor constant. This test consisted of dropping a known weight onto the mass of the seismometer and recording the peak output value. The weight was tiven removed and a step in current was applied to the calibration coil. This procedure was. then repeated until the resulting output amplitude was identical to that produced by the weight. Since the dropping of the weight and the step in current are both a step in force on the seismometer, the seismometer responds to both in the same 
manner. The motor constant is then found by equating the force of the weight to the force in the calibration coil as in Eq. (54). The value reported by the Geotech personnel was

$2.44 \mathrm{~N} / \mathrm{A}$.

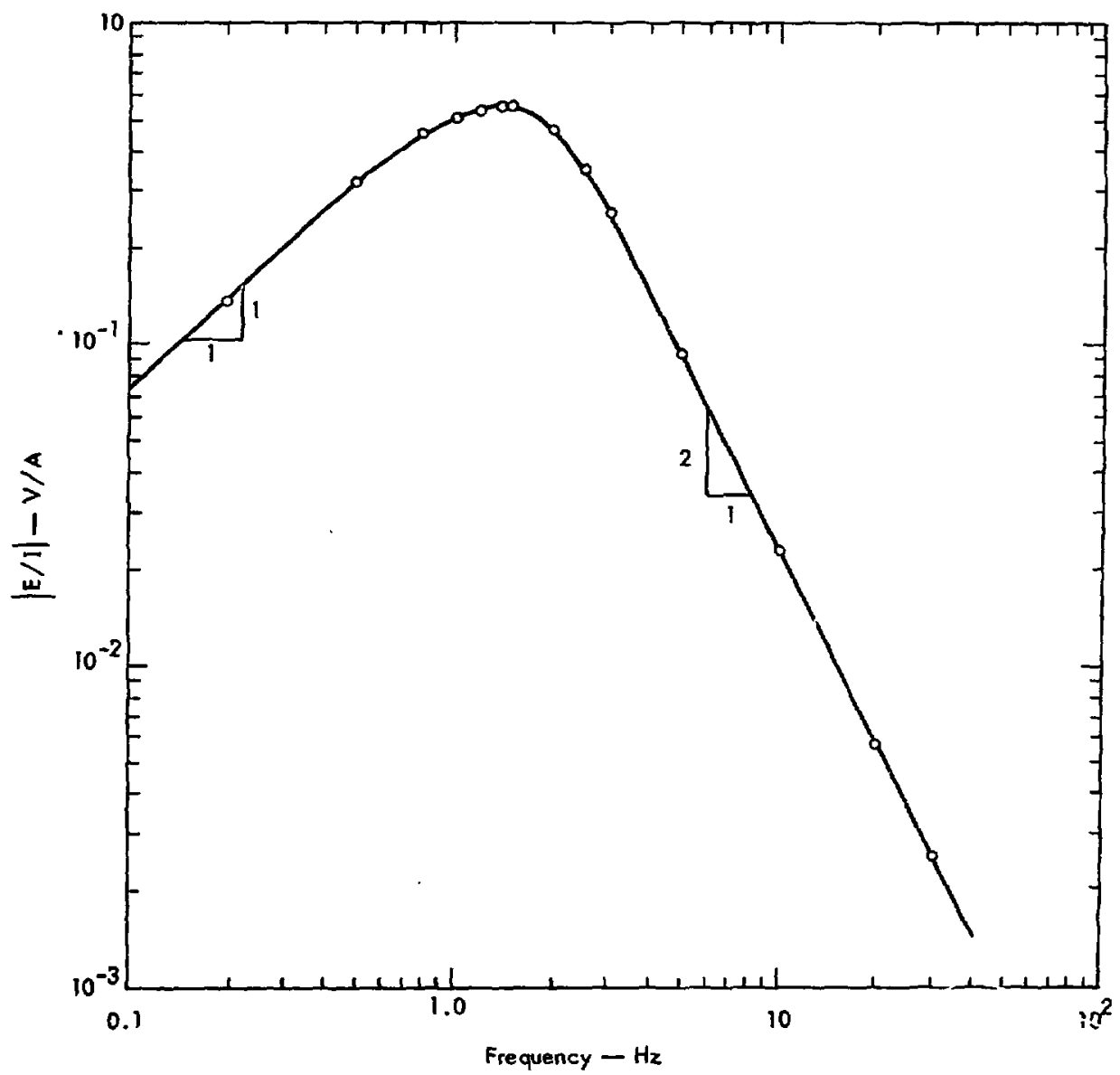

Fig. 9. Response of seismometer to sinusoidal current input in calibrated coil. 
Table 2. Calibration coil motor constant.

\begin{tabular}{cccccc}
\hline Frequency & $I(\mathrm{ma})$ & $E(\mathrm{mv})$ & $\mathrm{E} / \mathrm{I}\left(\frac{\mathrm{v}}{\mathrm{a}}\right)$ & $\mathrm{M}\left(\frac{\mathrm{v}}{\mathrm{m}}\right)$ & $\mathrm{G}\left(\frac{\mathrm{nt}}{\mathrm{amp}}\right)$ \\
\hline 0.2 & 110.6 & 15.25 & 0.138 & 11.07 & 2.117 \\
0.5 & 110.6 & 35.25 & 0.319 & 158.02 & 2.142 \\
0.8 & 110.6 & 49.75 & 0.450 & 559.2 & 2.186 \\
1.0 & 111.3 & 56.25 & 0.506 & 944.7 & 2.274 \\
1.2 & 110.6 & 59.25 & 0.536 & 1432.8 & 2.286 \\
1.5 & 110.6 & 61.49 & 0.553 & 2071.2 & 2.548 \\
2.0 & 110.6 & 51.5 & 0.466 & 3040.0 & 2.602 \\
2.5 & 110.6 & 38.50 & 0.348 & 3511.6 & 2.630 \\
3.0 & 110.6 & 28.5 & 0.258 & 3878.8 & 2.54 \\
5.0 & 110.6 & 10.25 & 0.0927 & 3900.7 & 2.52 \\
10.0 & 108.75 & 2.5 & 0.0230 & 3999.0 & 2.44 \\
20.0 & 103.75 & 0.586 & 0.00565 & 3979.0 & 2.560 \\
30.0 & 98.125 & 0.25 & 0.00255 & 3803.0 & 2.561 \\
\hline
\end{tabular}

Table 3. Confidence intervals.

\begin{tabular}{lccc}
\hline & $\begin{array}{c}\text { Degrees of } \\
\text { freedom }\end{array}$ & Coefficient & $\begin{array}{c}\text { Interval of true mean } \\
\text { (n/A) }\end{array}$ \\
\hline Weight lift test & 9 & $90 \%$ & $2.48-2.68$ \\
& & $95 \%$ & $2.46-2.70$ \\
Weight lift test & 5 & $98 \%$ & $2.43-2.73$ \\
& & $90 \%$ & $2.37-2.57$ \\
Dynamic test & $95 \%$ & $2.34-2.60$ \\
& \multirow{2}{*}{12} & $98 \%$ & $2.30-2.64$ \\
& & $90 \%$ & $2.38-2.56$ \\
& & $95 \%$ & $2.36-2.58$ \\
& & $98 \%$ & $2.33-2.61$ \\
\hline
\end{tabular}

\section{DAMPING AND LINE RESIST ANCES}

Figure 3 shows the damping and line resistances, $R_{d}$ and $R_{L}$. They are not well known because the line had been removed before this investigation. The damping resistor was used to adjust the overshoot ratio obtained on the ball lift test. Geotech personnel checked this ratio daily and corrected it by adjusting the damping resistance if it was greater than 20/1 or less than 12/1. Consequently, it was changed from time to time. No records of such changes were kept. The only available information is 
that on the day the seismometer, line termination module, and photo tube amplifier were returned to Livermore, the damping resistance, $R_{d}$, was set at $32 \Omega$. This value will be assumed to be representative of the damping resistace for lack of better information.

Whi:e the actual cable from the seismometer to the line termination module had been removed by the Geotech personnel on their departure, it is known that the cable run was approximately one-third of a mile of Spiral Four cable whose resistance is approximately $20 \Omega /$ mile." Thus, the cable had a resistance of about $7 \Omega$. In addition to this there were four lightning arrestors in the line, each with a resistance of approximately $2-1 / 4 \Omega 0^{\dagger}$ These two items result in a total line resistance of approximately $17 \Omega$ :

$$
\begin{aligned}
& \text { Cable } \quad \sim 1 / 3 \text { mile at } 20 \Omega / \text { mile }=\sim 7 \Omega \\
& \text { Lightning arrestors } \quad 4 \text { at } \sim 2-1 / 4 \Omega=\sim 9 \Omega \\
& \text { Total } \quad \mathbf{R}_{\mathrm{L}}=\sim 17 \Omega
\end{aligned}
$$

\section{PHOTOTUBE AMPLIFIER}

\section{Attenuator}

We used an $80-\Omega$ bridged $T$ attenuator on the input to the PTA galvanometer. This means that unless the input is loaded with $80 \Omega$, the combined resistances of the attenuator and load will vary with attenuator setting. This could mean that the damping of the galvanometer is a function of attenuator setting and therefore the response of the galvanometer would be affected every time the attenuator setting is changed, as shown by Eq. (32). To determine whether this is a problem, the seism ometer was connected to the line termination module which was in turn connected to the PTA (Fig. 3). The output side of the attenuator was then disconnected from the galvanometer and the impedance $\left[R_{x}\right.$ of $\left.E q .(18)\right]$ was measured as a function of damping resistance $\left(R_{d}\right)$ in the line termination module. Table 4 lists the results.

If the load on the attenuator is $80 \Omega$ and if $R_{g}=20.5 \Omega$ then the total damping load on the galvanometer is the sum of $R_{x}$ and $R_{g}$. Table 4 shows that the damping load is only affected significantly at the zero and $6-\mathrm{dB}$ settings. In actual usage at Mina, Nevada, the least attenuation used was $24 \mathrm{~dB}$ and a typical value was $36 \mathrm{~dB}$.

\section{Galvanometer Internal Resistance}

Using a digital multimeter, we measured the internal damping resistance. After the galvanometer had come to rest, $R_{g}$ equaled $20.5 \Omega$. This value is in agreement with the nominal design value of the Geotech specifications.

\footnotetext{
Personal communication with station operator.

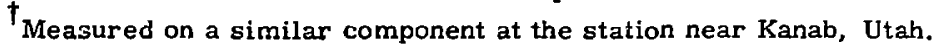


Table 4. External damping resistance as a function of attenuator setting.

\begin{tabular}{|c|c|c|c|c|c|c|}
\hline \multirow{2}{*}{$\begin{array}{l}\text { Attenuator } \\
\text { setting } \\
\text { (dB) }\end{array}$} & \multicolumn{3}{|c|}{$\mathrm{R}_{x}$ (ohms) } & \multicolumn{3}{|c|}{$\left(\mathrm{R}_{x}+\mathrm{R}_{g}\right) / 163.5$} \\
\hline & $R_{d}=0 \Omega$ & $R_{\mathrm{d}}=32 \Omega$ & $\mathrm{R}_{\mathrm{d}}=500 \Omega$ & $R_{d}=0 \Omega$ & $R_{d}=32 \Omega$ & $R_{d}=500 \Omega$ \\
\hline 0 & 102.2 & 112.3 & 148.8 & 0.75 & 0.812 & 1.035 \\
\hline 6 & 130.3 & 134.0 & 144.4 & 0.922 & 0.945 & 1.009 \\
\hline 12 & 139.7 & 140.7 & 143.4 & 0.980 & 0.986 & 1.002 \\
\hline 18 & 142.2 & 142.5 & 143.2 & 0.995 & 0.997 & 1.001 \\
\hline 24 & 142.8 & 142.9 & 143.1 & 0.999 & 0.999 & 1.000 \\
\hline 30 & 143.0 & 143.0 & 143.1 & 1.0 & 1.0 & 1.000 \\
\hline 36 & 143.0 & 143.0 & 143.1 & 1.0 & 1.0 & 1.000 \\
\hline 42 & 143.0 & 143.0 & 143.0 & 1.0 & 1.0 & 1.000 \\
\hline
\end{tabular}

\section{Galvanometer Natural Damping and Free Period}

We put the PTA galvanometer into free period vibration by setting the attenuator switch to zero. removing the input cable, and then applying a small transient voltage to the input terminals and removing it. We recorded the result on a strip chart and then plotted the peak-to-peak amplitudes one period apart (Fig. 10). Again, Eq. (52) was used to compute the natural damping from an average value of the natural log of the ratio of $A_{i}$ to $A_{i+1}$ found from the slope of the data of Fig. 9. From this data the natural damping of the PTA galvanometer was calculated to be

$$
h_{g}=0.004045 \text {. }
$$

The free period averaged over 48 cycles from the same test is

$$
\mathrm{T}^{\prime}=1 / 4.977 \mathrm{sec} .
$$

\section{Galvanometer Sensitivity and Moment of Inertia}

The ratio of the square of the sensitivity to the moment of inertia $\left(T_{g}^{2} / I\right)$ mathematically characterizes the galvanometer. This ratio together with the resistive load $\left(R_{g}+R_{x}\right.$ ) governs the damping and, therefore, the response of the system. The values $T_{g}$ and $I$ aid in designing the system since they control the amplitude of motion. However, in modeling the system, we have emphasized relative amplitude response because the final product of this study, the digital code, will be normalized to unit magnification at $1 \mathrm{~Hz}$.

The quantity $\mathrm{T}_{g}^{2} / \mathrm{I}$ can be found by experimentally evaluating Eq. (20). We used a function generator to drive an $80-\Omega$ matching network on the input to the PTA attenuator which was set at $42 \mathrm{~dB}$. The output of the function generator and the galvanometer (actually the photocells) were recorded on a Brush strip chart. The 


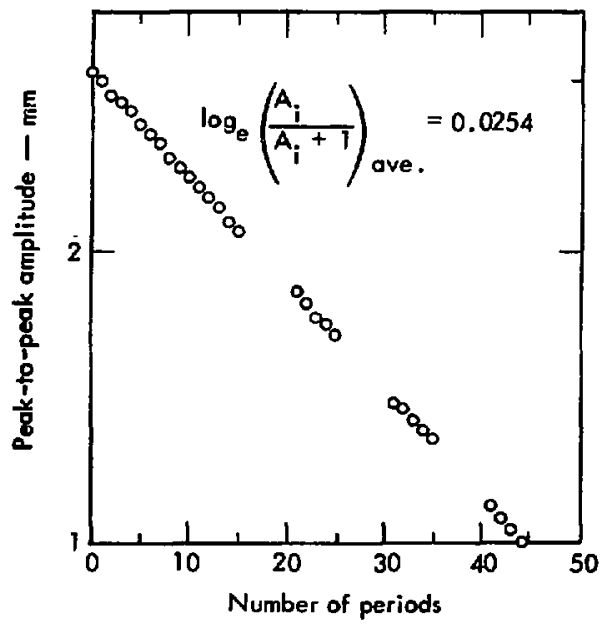

Fig. 10. PTA galvanometer free period damping test. results are listed in Table 5 and plotted in Fig. 11. We ran the zero frequency with a square wave whose period was ten times that of the galvanometer. Thus, the transient response of the galvanometer died out before the next cycle of the square wave.

Table 5 also lists the values of $\eta$ deduced from Eq. (20) and the experimental data. Note that the values of $\eta$ tend to increase on both ends. This may be explained by noisy data at the high frequency end and by the difficulty in dividing a poorly known small number by another small number at the low frequency end. Thus, the values of $\eta$ for frequencies 2 through 6 have been selected arbitrarily as the best data from which to calculate

a mean value of $\eta=0.675$.

The quantity $\mathrm{T}_{\mathrm{g}}^{2} / \mathrm{I}$ can now be determined using Eq. (19) and the previously found values of $h_{g^{\prime}} \omega_{g}$ and $R_{g^{*}}$ We have also determined that $R_{X}$ is $79.9 \Omega$.

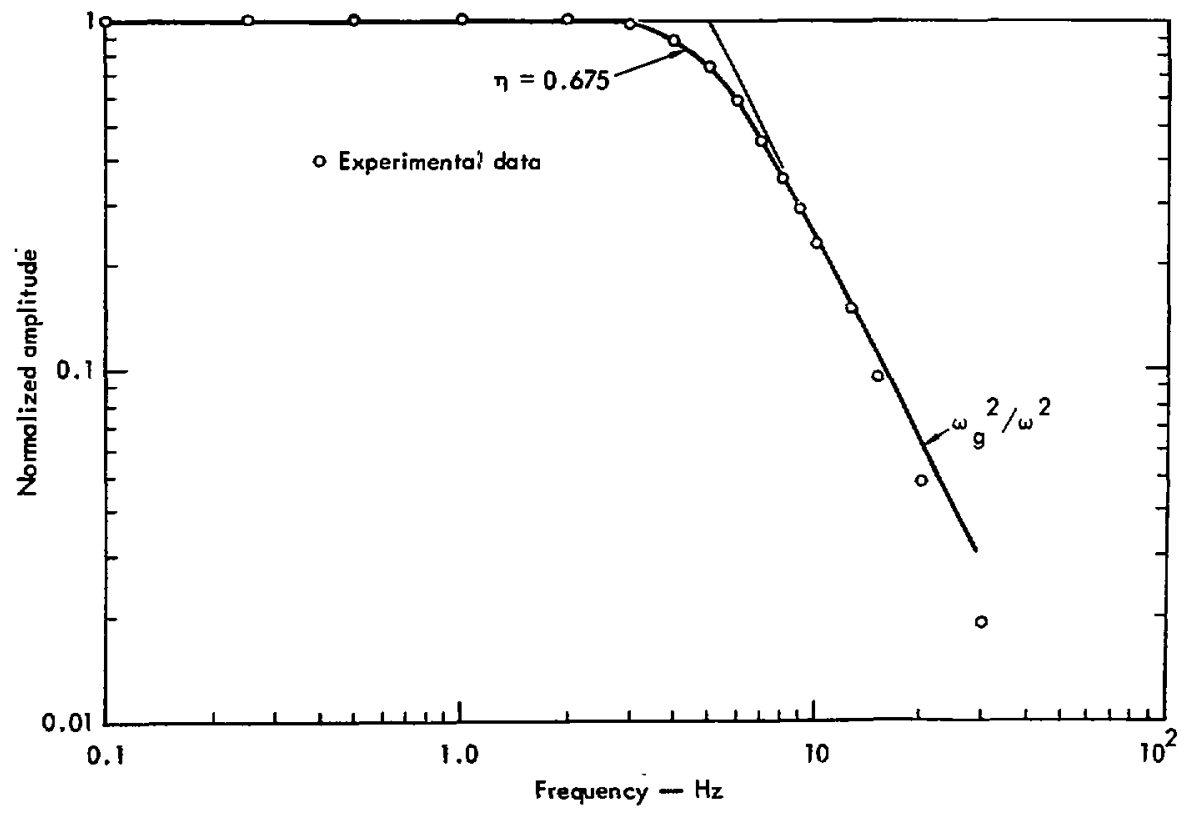

Fig. 11. PTA galvanometer frequency response. 
Table 5. Frequency response of the PT A galvanometer.

\begin{tabular}{llll}
\hline & $\begin{array}{c}\text { Relative } \\
\text { amplitude }\end{array}$ & & Eq. (20) \\
response & $\eta$ & $\eta_{\text {mean }}=0.675$ \\
\hline 0 & 1. & - & 1. \\
0.01 & 0.995 & - & 1. \\
0.05 & 1. & - & \\
0.1 & 0.996 & - & 1. \\
0.25 & 0.996 & - & 1. \\
0.5 & 0.991 & 0.9765 & 1.002 \\
1.0 & 0.996 & 0.7351 & 1.037 \\
2.0 & 1. & 0.6782 & 1.001 \\
3.0 & 0.973 & 0.6701 & 0.969 \\
4.0 & 0.881 & 0.6728 & 0.879 \\
5 & 0.746 & 0.6702 & 0.741 \\
6 & 0.589 & 0.6832 & 0.596 \\
7 & 0.454 & 0.708 & 0.472 \\
8 & 0.353 & 0.7579 & 0.375 \\
9 & 0.286 & 0.7458 & 0.303 \\
10 & 0.229 & 0.7933 & 0.248 \\
12.5 & 0.152 & 0.7930 & \\
15 & 0.097 & 1.08 & \\
20 & 0.048 & - & \\
30 & 0.019 & - & \\
\hline & & & \\
\hline
\end{tabular}

$$
\mathrm{T}_{\mathrm{g}}^{2} / \mathrm{I}=6861 \Omega / \mathrm{sec} .
$$

The value of $R_{x}$ which will result in critical damping, that is, $n=1$, is sometimes called CDRX for external critical damping resistance and is used by Geotech in their specifications. Applying $\mathrm{h}_{\mathrm{g}^{2}} \omega_{\mathrm{g}^{2}}$ and $\mathrm{R}_{\mathrm{g}^{2}}$ we find that CDRX is $89.6 \Omega$.

\section{PTA Filter}

We used the bandpass filter to eliminate $60-\mathrm{Hz}$ power line noise as well as long period orifts in the output voltage. Laboratory tests established that the $-3-\mathrm{dB}$ points are at $0.01 \mathrm{~Hz}$ and $10.0 \mathrm{~Hz}$, which are some of the available options specified in the Geotech manual. In other words, $\omega_{1}$ and $\omega_{2}$ of Eqg. (38) and (39), respectively, are

and

$$
\begin{aligned}
& \omega_{1}=0.02 \pi \\
& \omega_{2}=20 \pi
\end{aligned}
$$

$$
n=0.707 \text {. }
$$

\section{FILM RECORDER}

\section{Galvanometer Internal Resistance}

Using a digital multimeter, we measured the internal resistances of the four galvanometers in the film recorder. Table 6 lists these measurements.

Table 6. Galvanometer internal resistance.

\begin{tabular}{cc}
\hline $\begin{array}{c}\text { Cable } \\
\text { channel }\end{array}$ & $\begin{array}{c}\text { Galvanometer internal } \\
\text { resistance }\left(\mathbf{R}_{\mathbf{g}}\right) \\
(\Omega)\end{array}$ \\
\hline A & 20.5 \\
B & 18.8 \\
C & 20.9 \\
D & 19.1 \\
\hline
\end{tabular}

\section{Galvanometer Natural Damping and Free Period}

The film recorder has a switch setting that puts the galvanometer into free period. Free period tests were run on all four channels. However, the results were not measured with the same precision as on the free period 
test of the galvanometer in the PTA. Instead, the film from these tests was compared visually with the film from the PTA galvanometer test by overlaying one on the other. In each case the results were virtually identical. Thus, the natural damping for all four galvanometers is negligible (approximately 0.004 ) and the natural frequency is $5 \mathrm{~Hz}$.

\section{Galvanometer Termination}

Three of the four galvanometers have front panel controls labelled " $E-P$ Channel" while the fourth, Channel $D$, has a set labelled "AMP Channel". The chief difference is that the E-P panel has a damping control while the AMP panel does not. With this damping control the external damping resistance (Table 7) can be varied as follow:

Table 7. Range of external damping resistance.

\begin{tabular}{cc}
\hline Cr.annel & $\begin{array}{c}\mathbf{R}_{\mathbf{X}} \\
(\Omega)\end{array}$ \\
\hline A & $2-135$ \\
B & $4-144$ \\
C & $5-145$ \\
\hline
\end{tabular}

On Channel $D$ (the AMP panel) the external damping resistance is fixed at $16.9 \Omega$ and it cannot be changed.

\section{Galvanometer Sensitivity and Moment of lnertia}

Both the PTA galvanometer, and the ratio $\mathrm{T}_{\mathrm{g}}^{2} / \mathrm{I}$ were found by experimentally evaluating Eq. (20). However, the input to the E-P channels required a

60- $\Omega$ matching network while the AMP channel required a 22-k $\Omega$ matching network. The damping adjustments were not touched on the assumption that the settings were still the same as in the field. The external damping resistances at these settings were measured and the values recorded in Table 8 . We ran the frequency response

Table 8. External damping resistance used in frequency response test.

\begin{tabular}{cl}
\hline & $\begin{array}{l}\mathbf{R}_{\mathbf{X}} \\
(\Omega)\end{array}$ \\
\hline Channel & 88.8 \\
B & 78 \\
C & 97 \\
\hline
\end{tabular}
test with the Table 8 settings and the results were recorded in Table 9 . As before, the zero frequency datum was found from a step input, and $\eta$ was calculated from the normalized amplitude, Eq. (20), and the values of $\omega_{g}$ and $h_{g}$ given above.

As before, the computed value of $\eta$ begins to increase rapidly when the normalized amplitude is either close to unity or very small. Consequently, not

all computed values of $\eta$ were used to compute a mean vaiue. The selection was arbitrary but, in general, only high values from either end were omitted (as indicated in the table). We used the mean values from each channel to calculate $\mathrm{T}_{\mathrm{g}}^{2} / \mathrm{I}$ and $\mathrm{CDRX}$ (Table 10). 
Table 9. Frequency response of film recorder galvanometers.

\begin{tabular}{|c|c|c|c|c|c|c|c|c|}
\hline \multirow[b]{2}{*}{ Frequency } & \multicolumn{2}{|c|}{ Channel A } & \multicolumn{2}{|c|}{ Channel B } & \multicolumn{2}{|c|}{ Channel C } & \multicolumn{2}{|c|}{ Channel D } \\
\hline & $\begin{array}{l}\text { Normalized } \\
\text { amplitude }\end{array}$ & $\eta$ & $\begin{array}{l}\text { Normalized } \\
\text { amplitude }\end{array}$ & $\eta$ & $\begin{array}{c}\text { Normalized } \\
\text { amplitude }\end{array}$ & $\eta$ & $\begin{array}{l}\text { Normalized } \\
\text { amplitude }\end{array}$ & $n$ \\
\hline 0 & 1. & - & 1 & - & 1. & - & 1. & - \\
\hline 0.1 & 0.981 & - & 0.977 & - & 0.98 & - & 0.967 & - \\
\hline 0.3 & 0.971 & 2.17 & 0.955 & 2.68 & 0,958 & 2.5926 & 0.869 & 4.797 \\
\hline 1 & 0.914 & 1.312 & 0.796 & $2.0258^{\mathrm{a}}$ & 0.823 & 1.8621 & 0.498 & $4.4092^{\mathrm{a}}$ \\
\hline 2 & 0.784 & $1.1998^{\mathrm{a}}$ & 0.566 & $1.9427^{a}$ & 0.6018 & $1.7922^{2}$ & 0.277 & $4.3888^{a}$ \\
\hline 3 & 0.648 & $1.170^{\mathrm{a}}$ & 0.412 & 1.9511 & 0.4469 & $1.7868^{\mathrm{a}}$ & 0.19 & 4.3534 \\
\hline 4 & 0.521 & $1.178^{a}$ & 0.318 & $1.8495^{\mathrm{a}}$ & 0.346 & $1.7923^{\mathrm{a}}$ & 0.141 & 4.4269 \\
\hline $\mathbf{5}$ & 0.426 & $1.1748^{\mathrm{a}}$ & 0.255 & $1.9608^{\mathrm{a}}$ & 0.279 & $1.7921^{a}$ & 0.116 & 4.3103 \\
\hline 7 & 0.287 & 1.4037 & 0.179 & $2.0245^{a}$ & 0.195 & $1.8633^{\mathrm{a}}$ & 0.086 & $4.167^{\mathrm{a}}$ \\
\hline 10 & 0.172 & 1.6356 & 1157 & 2.2872 & 0.128 & 2.092 & 0.06 & $4.2336^{\mathrm{a}}$ \\
\hline 20 & 0.0495 & - & 0.0385 & - & 0.047 & - & 0.025 & - \\
\hline 30 & 0.0208 & - & 0.0188 & - & 0.0239 & - & 0.015 & - \\
\hline
\end{tabular}

Used to compute mean value of $\eta$.

Table 10. Film recorder galvanometer parameters.

\begin{tabular}{|c|c|c|c|c|c|c|}
\hline Channel & $\begin{array}{l}R_{X} \\
(\Omega)\end{array}$ & $\eta$ mean & $\begin{array}{l}\mathbf{R}_{\mathbf{g}} \\
(\Omega)\end{array}$ & $\begin{array}{c}\mathrm{T}_{\mathrm{g}}^{2} / \mathrm{I} \\
(\Omega / \mathrm{sec})\end{array}$ & $\begin{array}{c}\text { CDRX } \\
(\Omega)\end{array}$ & $\eta \mathrm{min}$ \\
\hline A & 88.8 & 1.18 & 20.5 & 8081 & 109 & 0.831 \\
\hline B & 78. & 1.96 & 18.8 & 11880 & 171 & 1.155 \\
\hline C & 97. & 1.82 & 20.9 & 13420 & 194 & 1.291 \\
\hline$D$ & 16.9 & 4.33 & 19.1 & 9778 & 137 & 4.33 \\
\hline
\end{tabular}

Table 10 shows that there is a wide variation between galvanometers, so much so, in fact, that only Channel $\mathrm{A}$ can be adjusted to critical damping, as indicated by the tabulated values of CDRX and $n$ min. 


\section{Recursive Code Calculations}

As pointed out in the introduction one objective of this study is to develop a digital filter to simulate the Benioff system; the system parameters were systematically measured for this purpose. However, the seismometer and film recorder galvanometer damping were subject to change by the operators and, consequently, system response was not constant from event to event nor even from channel to channel of the film recorder. Therefore, the problem is not to numerically duplicate one set of conditions, but rather to find a set of parameters which best reproduces the average or typical system response.

\section{CODE VERIFICATION AND PARAMETER MODIFICATIONS}

As presently set up, the code is intended to filter broad-band data transmitted over the seismic telemetry system, F.M. recorded on magetic tape, demodulated and digitized and stored on the computer photo-store facilities. A digitizing rate of $300 \mathrm{pt} / \mathrm{sec}$ has been used because this value allows $15 \mathrm{~min}$ of data from ten channels to be recorded on one digital tape. It also allows us to evaluate the discreet Fourier transform of portions of the signal up to $150 \mathrm{~Hz}$, which is approximately 15 to 30 times the pass band of the Benioff seismic system. The digitizing rate affects the response obtained from the finite difference approximation, that is, the lower the digitizing rate the greater the attenuation at a given frequency. Thus, some of the parameters measured in the previous section must be modified slightly to obtain the desired response at specified points in the passband. This is more important for the low pass than the high pass elements of the system.

\section{Seismometer}

Equation (13) shows that the inductance can be neglected for $\omega \leq \omega \mathrm{s}$ and that the inductance is the important term for $\omega \geq \omega_{s}$. Therefore, the seismometer and its inductance will be considered separately when determining modified parameters, that is, we will assume that the inductive term can be factored out of the expression for the response of the seismometer. The differential equation to be considered is derived from Eqs. (2) and (3) by assuming zero inductarce and replacing ground displacement with ground velocity. The result is

$$
\frac{d i^{2}}{d t^{2}}+2 \eta_{s} \omega_{s} \frac{d i}{d t}+\omega_{s}^{2} i=\frac{-k s}{R} \frac{d^{2} v}{d t^{2}},
$$

where

$$
n_{\mathrm{g}}=h_{\mathrm{s}}+\frac{k_{\mathrm{s}}^{2}}{2 \omega_{\mathrm{g}}{ }_{\mathrm{IM}} \mathrm{M}}
$$


The relative amplitude response is

$$
|\overline{\mathrm{i}}| \frac{\mathrm{R}}{\overline{\mathrm{v}}}=\frac{1}{\left[\left(\left(\frac{\omega_{\mathrm{s}}}{\omega}\right)^{2}-1\right)^{2}+\left(2 \eta_{\mathrm{s}} \frac{\omega_{s}}{\omega}\right)^{2}\right]^{1 / 2}}
$$

The relative amplitıde response to velocity of the recursive solution is derived from the $Z$ transform, 1 evaluated for

$$
\mathrm{Z}=\mathbf{e}^{-\omega \Delta t}
$$

The derivation yields

$\left|\frac{i(\omega)}{V(\omega)}\right| \frac{R}{k_{s}}=\frac{4 \sin ^{2} \frac{\omega \Delta t}{2}}{\left[\left(\omega_{s}^{2} \Delta t^{2}+4 B \sin ^{2}\left(\frac{\omega \Delta t}{2}\right)-2 \sin ^{2} \omega \Delta t\right)^{2}+(2 B \sin \omega \Delta t-\sin 2 \omega \Delta t)^{2}\right]^{1 / 2}}$,

where

$$
\mathrm{B}=1+\eta_{\mathrm{s}} \omega_{\mathrm{s}} \Delta \mathrm{t}
$$

and

$\Delta t=$ the time increment between points (the reciprocal of the digitizing rate).

Both Eqs. (60) and (62) approach $\left(\omega / \omega_{s}\right)^{2}$ for $\omega<\omega_{\mathrm{B}}$. However, Eq. (60) approaches unity for $w>w_{\mathrm{s}}$ whereas Eq. (62) becomes

$$
\frac{1}{1+\eta_{s} \omega_{s} \Delta t+\left(\frac{\omega_{s} \Delta t}{2}\right)^{2}}
$$

Equation (62) can only be made to approach unity by increasing the digitizing rate, which has already been fixed by other considerations. The altemative is to require that Eq. (62) equal Eq. (60) at a specified point in the pass band of the system.

Arbitrarily, then, Eqs. $(60)$ and (62) are evaluated at $\omega=\omega_{8^{*}}$ Assuming small angles, the result is

1. B. Gold and C. Rader, Digital Processing of Signals (McGraw-Hull, New York, 1969), Ch. 2 . 


$$
2 n_{s}=2\left(n_{s}^{\prime}+\frac{\omega_{s} \Delta t}{2}\right) \sqrt{1 \cdot+\left(\frac{\omega_{s} \Delta t}{2}\right)^{2}}
$$

where the prime denotes a modified value to be used in the recursive code. Evaluating Eq. (64) yields

$$
\eta_{\mathrm{s}}^{\prime}=\eta_{\mathrm{s}}-0.01047
$$

which implies that no modification should be required to obtain the desired response at $\omega=\omega_{s}$.

This is not the case for the inductive term, however. The reiative amplitude response of $\mathrm{Eq}$. (3) is

$$
\left|\frac{\bar{i}(\omega)}{\bar{v}(\omega)}\right|=\frac{1}{\sqrt{1+\left(\frac{\omega L}{R}\right)^{2}}}
$$

while the relative amplitude response of the recursive solution is

$$
\left|\frac{\mathbf{f}(\omega)}{\bar{v}(\omega)}\right|=\frac{1}{\left[1+\frac{4 L}{R \Delta t}\left(1+\frac{L}{R \Delta t}\right) \sin ^{2}\left(\frac{\omega \Delta t}{2}\right)\right]^{1 / 2}}
$$

Both Eqs. (65) and (66) are unity at $\omega=0$, but Eq. (66) is less than Eq. (65) for $0<\omega<\omega_{1}$. At $\omega=\omega_{1}$, Eq. (66) is again equal to Eq. (65), where $\omega_{1}$ is determined from

$$
\frac{\sin \left(\frac{\omega_{1} \Delta t}{2}\right)}{\frac{\omega_{1} \Delta t}{2}}=\frac{L}{\sqrt{R \Delta t}+L}
$$

A modified inductance $\left(L^{\prime}\right)$ can be found for small angles, that is $\frac{\omega \Delta t}{2}<6^{\circ}$ (frequencies up to $10 \mathrm{~Hz}$ ), by equating the approximate form of (66) to (65)

$$
\frac{L^{\prime}}{R^{2}}\left(R \Delta t+L^{\prime}\right)^{2}=\left(\frac{L}{R}\right)^{2}
$$


which, when solved, for $L^{\prime}$ yields

$$
L^{\prime}=-\frac{R \Delta t}{2}+\sqrt{L^{2}+\left(\frac{R \Delta t}{2}\right)^{2}} .
$$

Assuming $R=140 \Omega$ and $L=6.971 \Omega: \mathrm{sec}$, the modified inductance for $t=1 / 300 \mathrm{sec}$ is

$$
L^{\prime}=6.754 \Omega \cdot \mathrm{sec} \text {. }
$$

Equation (69) is included in the code.

Figure 12a shows the results of the recursive solution and the Fourier transform of the exact solution [Eq. (12)]. The latter has been evaluated for the following parameters

$$
\begin{array}{lll}
\omega_{S}=2 \pi 1 / \mathrm{sec} & M=107.5 \mathrm{~kg} & K_{\mathrm{g}}=355 \mathrm{vsec} / \mathrm{m} \\
h_{\mathrm{B}}=0.0096 & \mathbf{R}=139.9 \Omega & L=6.97 \Omega \cdot \mathrm{sec}
\end{array}
$$

To make the comparison in Fig. $11 \mathrm{a}$, we gave the recursive code the above parameters and calculated the current output of the seismometer for a unit impulse in velocity. This calculation was made using a finite difference approximation to Eq. (32). It was not made a permanent feature of the final code listed in the Appendix because it is incidental to the final result; it is only useful to verify the coding of Eq. (49). The finite Fourier transform (FFT) of the current was then computed. Note that the recursive solution matches the exact solution [Eq. (11)].

\section{PTA Galvanometer and Filter}

As both the galvanometer and the PTA filter are low pass filters, both can be described in general terms by the relative amplitude response of Eq. (39)

$$
\left|\frac{\bar{e}_{2}}{\overline{\mathrm{e}}_{1}}\right|=\frac{\omega_{2}^{2}}{\left[\left(\omega_{2}^{2}-\omega^{2}\right)^{2}+\left(2 \eta \omega_{2} \omega\right)^{2}\right]^{1 / 2}} .
$$

which is unity at $\omega=0$ and which approaches $\left(\omega_{2} / \omega\right)^{2}$ for $\omega>\omega_{2}$. The relative amplitude response of the recursive solution to Eq. (39) is

$$
\left|\frac{e_{2}(\omega)}{e_{1}(\omega)}\right|=\frac{\omega_{2}^{2} \Delta t^{2}}{\left[\left(\omega_{2}^{2} \Delta t^{2}+4 B \sin ^{2}\left(\frac{\omega \Delta t}{2}\right)-2 \sin ^{2} \omega \Delta t\right)^{2}+(2 B \sin \omega \Delta t-\sin 2 \omega \Delta t)^{2}\right]^{1 / 2}},
$$




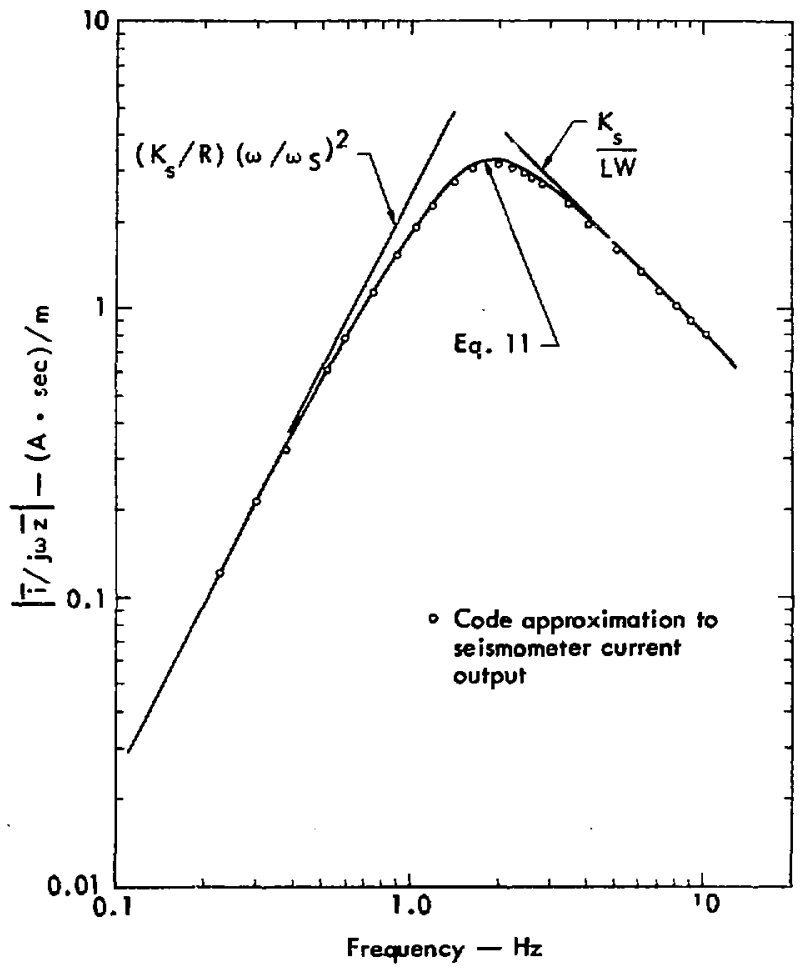

(a) Seismometer

Fig. 12. Response of finite difference approximations to the Benioff system.

where $B=1+\eta \omega_{2} \Delta t$. Equation $(71)$ is unity at $w=0$, but it does not approach $\left(\omega_{2} / \omega\right)^{2}$ when $\omega>\omega_{2}$, as does Eq. (70), but rather is less than it up to a point, beyond which it is larger than Eq. (70). To ensure that Eq. (70) and (71) have the same attenuation at $\omega_{2}$ we used a modified value $\left(\eta^{+}\right)$in Eq. (70). Both Eqs. (70) and (71) are evaluated at $\omega_{2}=10 \pi$, and then equated. The resultant is then solved for $\eta^{\prime}$

$$
\eta^{\prime}=1.00044 \eta-0.05235 \text {, }
$$

where $\eta^{\prime}$ is the mouiinied value to be used in Eq. (71). In the previous section $\eta$ was found to be 0.675 . Thue,

$$
\eta^{\prime}=0.622,
$$




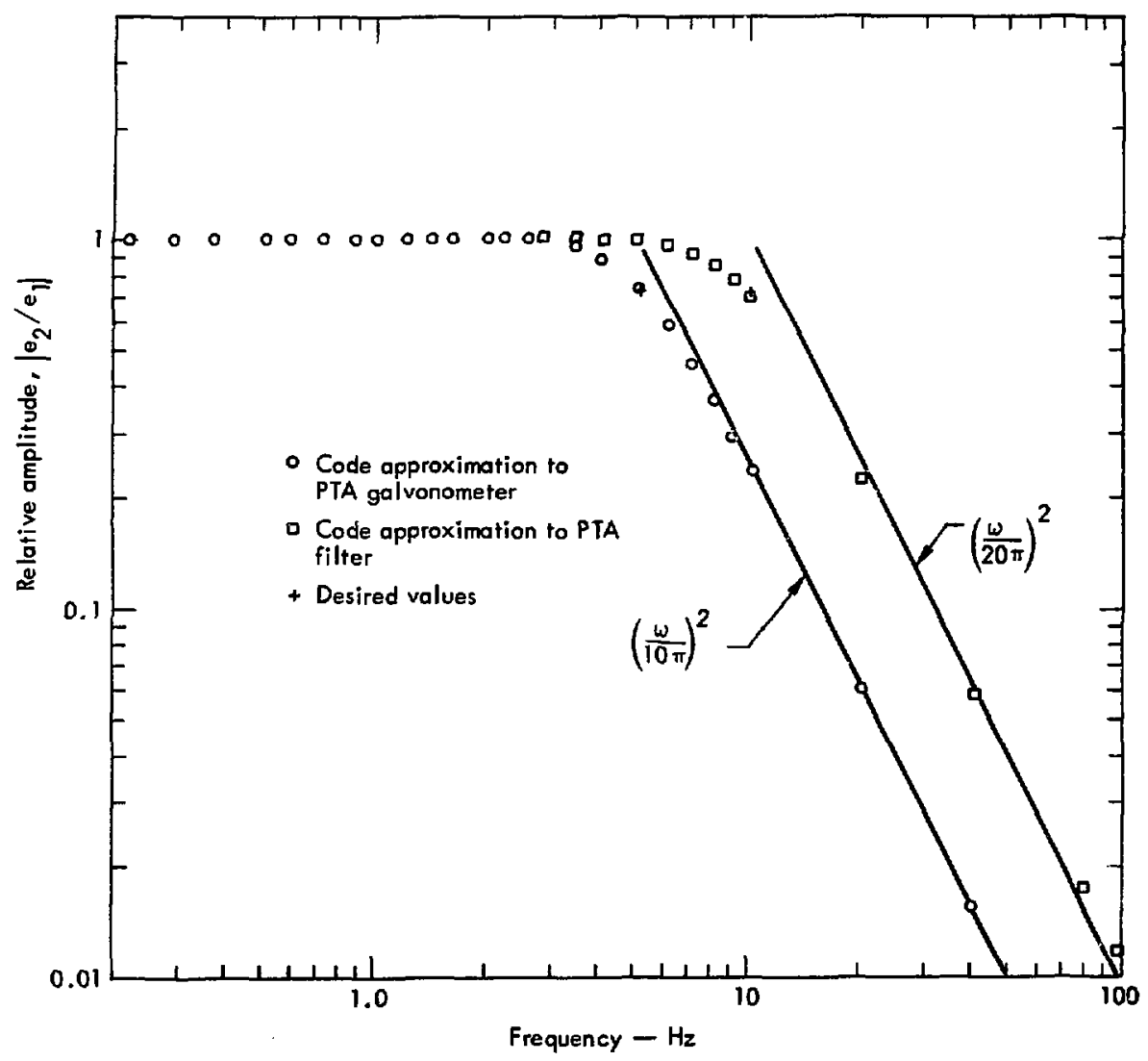

(b) PT A galvanometer and filter.

Fig. 12 (cont.)

which in turn implies

$$
T_{g}^{\prime}=79.42
$$

The PTA filter is treated similarly. Previously, the PTA filter was down $3 \mathrm{~dB}$ at $\omega_{2}=20 \pi$, i. e., at $\omega_{2}=20 \pi$ the relative amplitude response is 0.707 . Following the procedure outlined above, the modified value is

$$
\eta^{\prime}=0.604
$$


The high pass section of the PTA is represented by Eq. (38), whose relative amplitude response is

$$
\left|\frac{\bar{e}_{1}}{\bar{e}_{0}}\right|=\frac{\omega}{\sqrt{\omega^{2}+\omega_{1}^{2}}} .
$$

wh:ch approaches unity for $\omega>\omega_{1}$ and approaches $\left(\omega / \omega_{1}\right)$ for $\omega<\omega_{1}$. The relative amplitude response of the recursive solution is

$$
\left|\frac{\bar{e}_{1}(\omega)}{\bar{e}_{0}(\omega)}\right|=\frac{2 \sin \left(\frac{\omega \Delta t}{2}\right)}{\sqrt{\left(1-\cos \omega \Delta t+\omega_{1} \Delta t\right)^{2}+\sin ^{2} \omega \Delta t}} .
$$

which is nearly identical to Eq. (73). Therefore, no modification is required on the high pass section.

Figure 12b shows the responses of the recursive solutions which simulate the PTA galvanometer and filter. Note that the desired response has been achieved. Again, as in the case of the current from the seismometer, we have calculated the response curves using the FFT of the impulse response of the recursive equations.

\section{Film Recorder Galvanometers}

The damping terms in the recursive solutions for the film recorder and in the PT A galvanometer require the same modification [given by Eq. (72)]. However, as the correct damping is not known, a range of values must be considered. Table 8 liste damping terms and minimum possible damping. For each of the damping terms a corresponding modified value has been calculated using Eq. (72) (Table 11).

Table 11. Modified film recorder damping values.

\begin{tabular}{ccccc}
\hline Channel & $\eta_{\text {test }}$ & $\eta_{\text {test }}^{\prime}$ & $\eta_{\text {min }}$ & $\eta_{\text {min }}^{\prime}$ \\
\hline $\mathrm{A}$ & 1.18 & 1.128 & 0.831 & 0.779 \\
$\mathrm{~B}$ & 1.96 & 1.909 & 1.155 & 1.103 \\
$\mathrm{C}$ & 1.82 & 1.768 & 1.291 & 1.239 \\
\hline
\end{tabular}

\section{SEISMOMETER AND FILM RECORDER DAMPING: CRITERIA AND PARAMETER STUDY}

During the period of overlap of the two systems, 18 of the events recorded by the broad band system were digitized. These events form the basis for evaluating the 
digital filter in the same way as the electronic filter was evaluated. Following each of these events, the operators ran a routine free period, ball lift, and an eight point frequency response test, all of which vary from event to event. The ball lift test will be used to choose the seismometer damping while the frequency response test will be used to choose the film recorder galvanometer damping.

\section{Free Period Tests}

To determine the free period for the 18 events we measured the time required for a minimum of six complete cycles. The values range from $0.99 \mathrm{sec}$ to $1.099 \mathrm{sec}$, with a mean and standard deviation of $1.02 \pm 0.03 \mathrm{sec}$. No explanation for this variation is available. However, the speculation is that the mass drifted about its center position and that the period is a function of the mass position. This cannot be confirmed because all efforts to measure the free period at various positions were unsuccessful.

\section{Ball Lift Tests}

The ball lift test consists of alternately lifting and dropping a small weight on the mass of the seismometer and then lifting it off. Essentially, the response of the system results from seismometer damping and the high pass section of the PTA filter. The latter, however, is fixed and known. Consequently, any changes can be attributed to changes in the damping potentiometer. Furthermore, the effect of the film recorder response is so small over the range of its most likely damping values that the ball lift test provides a good criterion for choosing the seismometer damping.

Figure 13 shows the system response to one such test, which has been traced from a 12.05X enlargement of the $35-\mathrm{mm}$ film from Channel $B$. The ratio of the amplitudes $X_{1}$ and $X_{2}$, shown in Fig. 13 , is called the damping over-shoot ratio. The

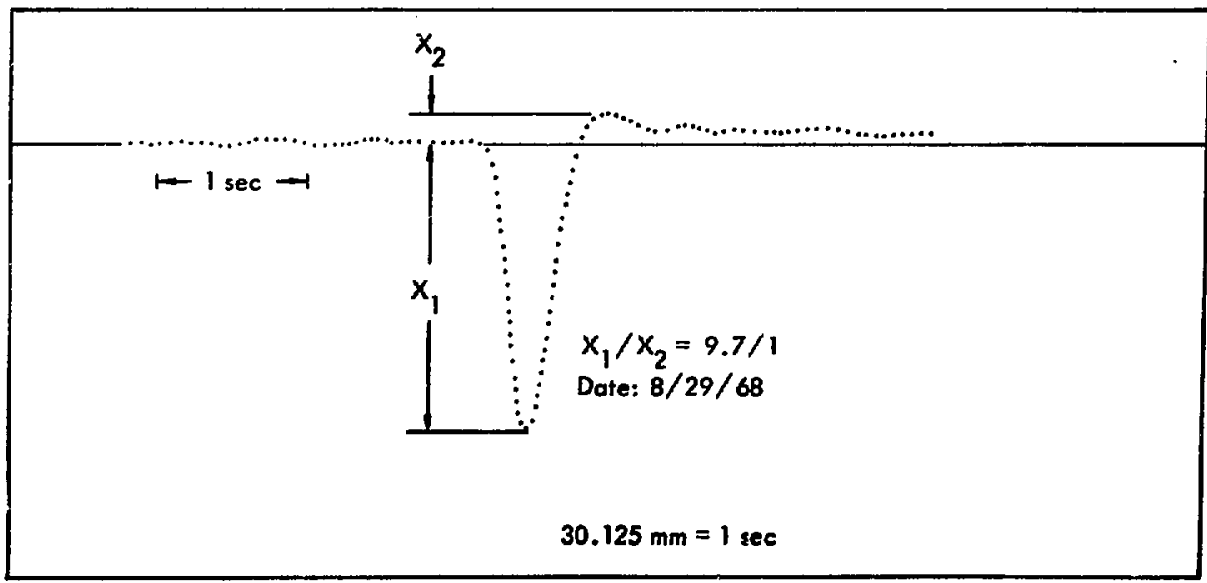

Fig. 13. Channel B response to a ball lift test. 
long tail on the response results from the high pass section of the PTA filter. That tail makes measurement of $\mathrm{x}_{2}$ difficult and somewhat uncertain because the base line must be extrapolated from the trace aheaj of the test. The operators usually applied about a half dozen tests only $10 \mathrm{sec}$ apart, which is too short a time for the PTA filter to return to zero. This makes the determination of the base line even more difficult and the measurement more uncertain. For this reason only the first of the ball lift tests was measured for any given event. For the 18 events under consideration the range was from 8.8 to 11.2 with a mean and a standard deviation of $9.71 \pm 0.62$.

We made a parameter study with the recursive code to determine a damping resistance which would yield the mean damping overshoot ratio. The calculation included the PTA filter but excluded the film recorder, that is, the results of Eq. (50) were printed for an input step in force. The damping resistance shown in Fig. 14 includes the contribution of the line resistance. The input to the code was

$\Delta t=1 / 300 \mathrm{sec}, \mathrm{h}_{\mathrm{s}}=0.0096, \mathrm{f}_{\mathrm{s}}=1.0 \mathrm{~Hz}, \mathrm{~K}_{\mathrm{s}}=355 \mathrm{Vsec} / \mathrm{m}, \mathrm{M}=107.5 \mathrm{~kg}$ $\mathrm{L}=6.97 \Omega \mathrm{sec}, \mathrm{T}_{\mathrm{g}}^{\prime}=79.42 \mathrm{Vsec}, \mathrm{I}=1 \mathrm{nt} \mathrm{msec}^{2}, \mathrm{~h}_{\mathrm{g}}=0.004, \mathrm{f}_{\mathrm{g}}=5.0 \mathrm{~Hz}$.

In Fig. 14 the damping resistance that corresponds to a damping overshoot ratio of 9.7 is $61.5 \Omega$. We made four calculations with $R_{d}=61.5 \Omega$. Film recorder damping factors are $0.7,0.9,1.1$, and 1.9. The output of the film recorder [Eq. (51)] was printed out. The damping overshoot ratios were $9.69,9.70,9.9$, and 12.5, respectively. As it turns out the last of these is of no interest.

\section{Frequency Response Tests}

The Geotech personnel ran the routi.e frequency response tests by applying a sine in current to the calibration coil. One current level was used on each channel,

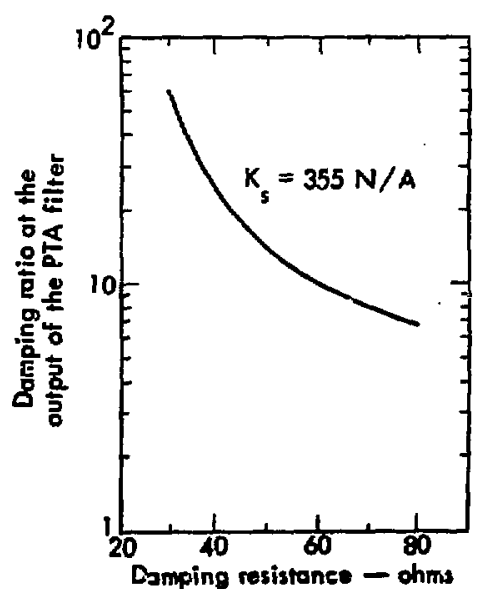

Fig. 14. Ratio $X_{1} / X_{2}$ vo damplng resistance. each of which was returned to its routine attenuator settings following an event, assuming additional attenuation was required for the event. One difficulty with this is that the lowest and the highest frequencies run $(0.3$ to $0.5 \mathrm{~Hz})$ were often very noisy because the seismometer response (Fig. 9) at these frequencies was small compared with the center frequency of about $1.5 \mathrm{~Hz}$. Consequently, the measurement of response amplitude on film is more uncertain on either end of the spectrum than in the middle.

Note that when tested in the lab, Channel A's normaltzed frequency response was higher at the high frequency 
end of the spectrum than were Channels $B$ and $C$, both of which were nearly the same. Since five events were recorded on Channel A, ten on Channel B, and three on Channel C, systematic differences can be expected between events recorded on Channel $A$ and those recorded on Channels $B$ or $C$. Thus, all the amplitudes of the frequency response tests were read for Channels $A$ and $B$. The mean and standard deviation of the response for each frequency over the set of 18 events were calculated. The values listed in Table 12 have been normalized to the response at $1 \mathrm{~Hz}$. These values are shown in Fig. 15 a. Note that the overall system response through Channel $A$ is broader than

Table 12. Mean and standard deviation of system response following 18 events.

\begin{tabular}{clll}
\hline $\begin{array}{c}\text { Frequency } \\
(\mathrm{Hz})\end{array}$ & \multicolumn{1}{c}{ Channel A } & \multicolumn{1}{c}{ Channel B } & Event channel \\
\hline 0.3 & $0.1058 \pm 0.0029$ & $0.1114 \pm 0.0025$ & $0.1099 \pm 0.0044$ \\
0.5 & $0.2918 \pm 0.0073$ & $0.304 \pm 0.004$ & $0.3011 \pm 0.0074$ \\
0.7 & $0.548 \pm 0.0065$ & $0.5651 \pm 0.0038$ & $0.560 \pm 0.01$ \\
1.5 & $1.532 \pm 0.041$ & $1.458 \pm 0.029$ & $1.483 \pm 0.045$ \\
2.0 & $1.558 \pm 0.08$ & $1.414 \pm 0.066$ & $1.455 \pm 0.078$ \\
3.0 & $1.120 \pm 0.10$ & $0.919 \pm 0.070$ & $0.977 \pm 0.104$ \\
5.0 & $0.403 \pm 0.075$ & $0.3044 \pm 0.0375$ & $0.334 \pm 0.057$ \\
\hline
\end{tabular}

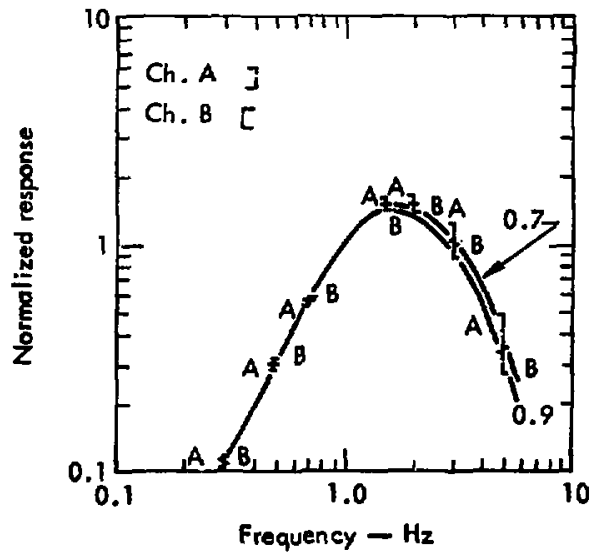

(a) Mean and standard deviation channels $A$ and $B$ on 18 occasions.

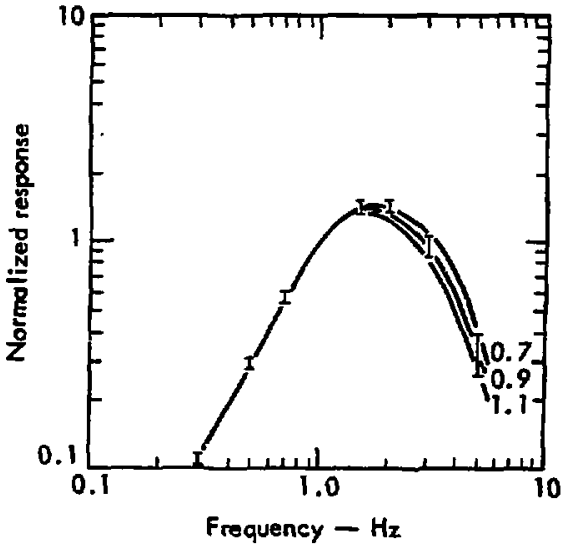

(b) Mean and standard deviation of event channel response on 18 events.

Fig. 15. Mean and standard deviation of Benioff systems response. 
through $B$ or $C$. If we assume that an event was large enough to be read on Channel $B$ but not large enough to clip (or go off the film on Channel $A$ ) then the reduced or scaled amplitude of the event, as read from Channel A, would be larger than Channel B's amplitude.

Nevertheless, we still have to find one set of parameters for the digital filter which will satisfactorily reproduce the film data from the digitized data. Therefore, we calculated the mean and standard deviation of the overall system response based on the test results from the same channel on which the event was recorded. (See Table 12 and Fig. 15b.)

Table 11 gives a range of 0.78 to 1.96 for modified film recorder damping values. Therefore, four sets of code calculations were made based on the parameters of the previous section and on $\eta_{f}=0.7,0.9,1.1$, and 1.9 , respectively. In each set we calculated the response to $0.3,0.5,0.7,1.0,1.5,2.0,3.0$, and $5.0 \mathrm{~Hz}$ sine waves in ground velocity. The results were then normalized to $1 \mathrm{~Hz}$ and plotted in Figs. $15 \mathrm{a}$ and $b$. Figure 15 a seems to show that Channel $A$ would be best represented by a film recorder damping factor of about seven tenths of critical, while Channel $r$ would be best represented by a film recorder damping factor of about critical. A factor of 1.9 (Table 12) seems out of the question. Figure 15b shows that the 0.7 case has the best fit for the center of the spectrum but not the ends, the 0.9 case fits well on the ends but not in the center, the 1.1 case fits well only on the low end of the spectrum, and the 1.9 case is so far off it hasn't been shown.

No one case is clearly superior, and the final choice will have to be based on how well the filtered data for the three cases just discussed reproduce the film data.

\section{COMPARISON OF DIGITALLY - FILTERED DATA WITH FILM DATA}

In this sectioi. we compare three sets of filtered amplitudes with the same mplitudes recorded on film. The film data have been scaled to displacement in millimicrons by dividing the amplitude on the film trace by the system magnification

$1 \mathrm{~Hz}$. Consequently, the recursively fistered data have also been scaled to dis placement at $1 \mathrm{~Hz}$.

\section{Scaling of Filtered Data}

In the cod the constants $C_{0}, C_{1}$, and $C_{2}$ of Eqs. (44), (45), and (46), respectively, have been lumped together into one constant called SCALE, which can be used to scale the filtered data in ${ }^{+}$whatever units are desired. In this case the desired result is . Fisplacement at $\mathbf{I ~ H z}$, i.e., set SCALE equal to the reciprocal of the magnification at $1 \mathrm{~Hz}$

$$
\operatorname{SCALE}=\frac{1}{\mathrm{M}_{1}}=\frac{1}{2 \pi \mathrm{V} \cdot \mathrm{S}_{1}}
$$


where V.S. is the velocity sensitivity at $1 \mathrm{~Hz}$. The velocity sensitivity can be found directly because the code operates on ground velocity [see Eq. (44)]. Thus, SCALE is initially set equal to unity and the code is simply given a sine wave whose amplitude is taken to be $1 \mathrm{~mm} / \mathrm{sec}$ (the broad band data are in units of velocity). The velocity sensitivity is then

$$
\text { V. S. } 1=\left(\frac{\text { Code Output }}{\text { Ground Velocity }}\right)_{1 \mathrm{~Hz}} \mathrm{sec} / \mathrm{mm}
$$

where the code output is taken to be dimensionless. The velocity sensitivity, magnification, and SCALE at $1 \mathrm{~Hz}$ for the three filters are given in Table 13.

Table 13. Velocity sensitivity, magnification, and SCALE at $1 \mathrm{~Hz}$ for three filters. ${ }^{a}$

\begin{tabular}{ccccc}
\hline Filter & $\eta_{\mathrm{f}}$ & $\mathrm{V}_{. \mathrm{S}}{ }_{1}(\mathrm{sec} / \mathrm{mm})$ & $\mathrm{M}_{1}(1 / \mathrm{mm})$ & SCALE $(\mathrm{mm})$ \\
\hline 1 & 0.7 & $8.0669 \times 10^{-4}$ & $5.069 \times 10^{-3}$ & 197.294 \\
2 & 0.9 & $7.8628 \times 10^{-4}$ & $4.94 \times 10^{-3}$ & 202.415 \\
3 & 1.1 & $7.6293 \times 10^{-4}$ & $4.794 \times 10^{-3}$ & 208.610 \\
\hline
\end{tabular}

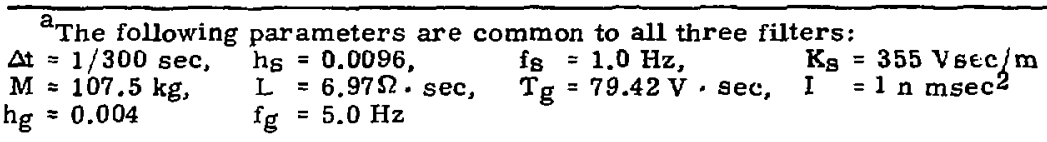

\section{Filtered Data Compared with Film Data}

The 18 events mentioned previously have been filtered using three sets of parameters. The only difference between the three filters is the film recorder damping factors and the corresponding SCALE values. Table 14 lists the amplitudes found by the cursive filters and subsequently recorded on film. In this table amplitude a is the first positive peak, $b^{\prime}$ is the first negative peak, and $c^{\prime}$ is the second positive peak. All three amplitudes are measured from base line to peak. Thess amplitudes were then used to obtain a linear regression fit to the following equation

$$
\log (\text { film amplitude })=E 1+\text { E2 } \log (\text { filter amplitude }) .
$$

The results obtained and the standard deviation from the fit are listed in Table 15 . For comparison the same results for the electronic filter currently in use are also shown. Note that all three recursive filters out-perform the analog filter in terms of standard deviation and nearness to unit slope. This is particularly true on $c^{\prime}$. However, the choice of the best filter is not immediately obvious from the table. Ideall; , the one nearest to unit slope and with the smallest standard deviation would be the best choice. No one filter has both of these properties, but filter 2 comes close. It has nearly the same mean slope as filter 3 and it has a better mean deviation. 
Table 14. Event amplitudes from film and from recursive filters.

\begin{tabular}{|c|c|c|c|c|c|c|c|c|c|c|c|c|}
\hline \multirow[b]{2}{*}{ Itannel } & \multicolumn{3}{|c|}{ Benioff film } & \multicolumn{3}{|c|}{ Filler $1 \pi r=0 . T$} & \multicolumn{3}{|c|}{ filter $2 \pi \xi=0 .:^{\prime}$} & \multicolumn{3}{|c|}{ rister $3 n t=1,1$} \\
\hline & $a$ & $\mathbf{b}^{\prime}$ & $\mathrm{c}^{\prime}$ & $a$ & $b^{\prime}$ & $c^{\prime}$ & a & $b^{\prime}$ & $\mathrm{c}^{1}$ & $a$ & $b^{\top}$ & $c^{\prime}$ \\
\hline A & 11.6 & 31.1 & 42.7 & 10,95 & 30.4 & 39.1 & 20.3 & 28.3 & 36.7 & 9.9 & 26.2 & 34.4 \\
\hline$A$ & 14.4 & 39.2 & 43.8 & 13.89 & 36.3 & +1.9 & 13.4 & 33.2 & 30.6 & 33.05 & $30 . \bar{t}$ & 37.6 \\
\hline A & 27.1 & 95.9 & 82.1 & 25.3 & 91.9 & 77.4 & 24.0 & 85.7 & 76.5 & 22.9 & 80.8 & 75.1 \\
\hline B & 32.2 & 27.8 & 98.2 & 34.5 & 128.4 & 102.8 & 32.8 & 120.1 & 92,4 & 31.4 & 114.9 & 83.9 \\
\hline B & 41.5 & 151.5 & 130.5 & $\$ 1.4$ & $262 . \hat{5}$ & 152.2 & $3 n$ & 152.0 & 232.4 & 38.3 & 131.2 & 216.6 \\
\hline A & 41.7 & 133.3 & 146.7 & 40.2 & $12 \pi .2$ & 133.3 & $3 B .1$ & 117 & 120 & 36.5 & 109 & 108 \\
\hline$A$ & 53.8 & 134.2 & 197.8 & 52.5 & 131.2 & $100 . !$ & 49.9 & 125.2 & 185,5 & +7.9 & 120.4 & 180.6 \\
\hline H & 54.3 & 170.7 & 255.3 & 48.4 & 187.2 & 253.9 & +5.8 & 175.7 & $232 . T$ & 43.7 & 166.5 & 214.9 \\
\hline IS & 162 & 557 & 259 & 170.4 & 584.5 & 305,3 & 163.1 & 547.8 & 264.7 & 157.4 & 517.8 & 234.2 \\
\hline 日 & 493 & $1,34 \pi$ & 813 & 500 & 1,350 & $1,22: 2$ & & 1.311 & 1,141 & +59 & 1,270 & 1,062 \\
\hline$c$ & 506 & 1.494 & 1.796 & 523 & 1,587 & 1,955 & 496.4 & 1,513 & 1,198 & $\$ 75.8$ & 1,450 & 1,663 \\
\hline B & 584 & 1,196 & 179 & 560 & 1,338 & 232 & 553 & 1,211 & 167 & 532 & 1,112 & 109 \\
\hline c & 1,085 & 2,365 & 1,665 & 1.086 & $2,57 \pi$ & 1,817 & 1,041 & 2,457 & 1,648 & 1,006 & 2,361 & 1,577 \\
\hline$B$ & 3,150 & 8,670 & 5,190 & 3,016 & 9,150 & 5,460 & 2,882 & 8,541 & 4,073 & 2,776 & 8,055 & 4,540 \\
\hline $\mathrm{B}$ & 3,230 & 6,000 & 2,700 & $3,12 \mathrm{~B}$ & $6,22 \mathrm{I}$ & 2,686 & 2,1984 & 5,895 & $2,+43$ & 2,883 & 5,633 & 2,206 \\
\hline $\mathbf{B}$ & 7,110 & 12,390 & 5,610 & 6,939 & 12,787 & 5,718 & 6,610 & 12,144 & 4,908 & 6,352 & 11,616 & 4,187 \\
\hline $\mathbf{B}$ & 8,400 & 19,600 & 9,800 & 8,787 & 22,044 & 11,510 & 8,433 & 20,600 & 10,172 & 8,154 & 19,452 & 9,007 \\
\hline$c$ & 29,500 & 60,200 & 6,700 & $2 \mathrm{~B}, 792$ & 63,809 & 13,914 & 27,761 & 59.869 & 10,028 & 26,956 & 56,609 & 7,205 \\
\hline
\end{tabular}

Table 15. Regults of linear regression fit.

\begin{tabular}{|c|c|c|c|c|}
\hline Filter & Amplitude & EI & E2 & $\sigma(\%)$ \\
\hline 1 & $\begin{array}{c}a \\
b^{\prime} \\
c^{\prime} \\
\text { mean }\end{array}$ & $\begin{array}{l}0.016047 \\
0.022190 \\
0.108315 \\
0.049\end{array}$ & $\begin{array}{l}0.995926 \\
0.986919 \\
0.944798 \\
0.976\end{array}$ & $\begin{array}{r}4.69 \\
5.12 \\
19.52 \\
9.78\end{array}$ \\
\hline 2 & $\begin{array}{c}a \\
b^{\prime} \\
c^{\prime} \\
\text { mean }\end{array}$ & $\begin{array}{l}0.040161 \\
0.058293 \\
0.113011 \\
0.070\end{array}$ & $\begin{array}{l}0.994516 \\
0.984074 \\
0.960573 \\
0.980\end{array}$ & $\begin{array}{c}4.87 \\
5.16 \\
14.9 \\
8.3\end{array}$ \\
\hline 3 & $\begin{array}{c}a \\
b^{\prime} \\
c^{\prime} \\
\text { mean }\end{array}$ & $\begin{array}{l}0.059996 \\
0.088467 \\
0.132992 \\
0.094\end{array}$ & $\begin{array}{l}0.993244 \\
0.981919 \\
0.971769 \\
0.982\end{array}$ & $\begin{array}{r}5.05 \\
5.75 \\
16.49 \\
9.1\end{array}$ \\
\hline electronic & $\begin{array}{c}a \\
b^{\prime} \\
c^{\prime} \\
\text { mean }\end{array}$ & $\begin{array}{l}-0.045827 \\
-0.020299 \\
0.112427 \\
0.015\end{array}$ & $\begin{array}{l}0.994696 \\
0.983359 \\
0.914014 \\
0.964\end{array}$ & $\begin{array}{r}6.73 \\
7.52 \\
25.82 \\
13.36\end{array}$ \\
\hline
\end{tabular}

Therefore, number 2 would seem to be the best choiz_ iv simulate the mean operating conditions of the old Benioff system.

To measure amplitudes b' and $c^{\prime}$ we denart from the traditional practice of measuring peak-to-peak amplitudes. That is, we traditionally measure from the first positive peak to the first negative peak for $b$ and from the first negative peak to the second positive peak for $c$. The following relationships then hold: 


$$
b=a+b^{\prime}
$$

and

$$
c=b^{\prime}+c^{\prime} \text {. }
$$

With this scheme of measuring, we obtained a smaller standard deviation in $c$ than in $c^{\prime}$ because $b^{\prime}$ is, in general, as large as or larger than $c^{\prime}$. Similarly, a smaller deviation is found for $b$ than for $b^{\prime}$. The results of a regression fit to Eq. (77) for $b$ and $c$ are given in Table 16.

Table 16. Results of regression fit for filter 2 using normal method.

\begin{tabular}{cccc}
\hline Amplitude & E1 & E2 & $\sigma(\%)$ \\
\hline $\mathrm{b}$ & 0.055687 & 0.987263 & 4.14 \\
$\mathrm{c}$ & 0.076569 & 0.979419 & 6.12 \\
\hline
\end{tabular}

However, this method of measurement is deceptive because the second positive peak appears to be better known than it really is. This effect is clearly seen in Fig. 16 where the recursive filter output for the last event listed in Table 14 is scaled to displacement in microns at $1 \mathrm{~Hz}$ for the three filters. Also shown is the film data for the last event listed in Table 14. The film data were read manually with a microscope equipped with X-V readout on a card punch machine. Therefore, the dala are not even spaced. Note that filter 1 is closest on amplitude a, filter 2 on amplitude $b^{\prime}$, and filter 3 is nearest on amplitude $c^{\prime}$. Clearly, the first method of measurement gives the best indication of how well the filter is reproducing the film data.

\section{Conclusions}

We have written a recursive code which satisfactorily reproduces the Benioff film data. Considerable effort was required to measure the physical parameters which describe the system. Unfortunately, seismometer and film galvanometer damping could not be reconstructed in the lab and we had to deduce these value? from the rcutine ball lift and frequency response tests run by the Geotech personnel ano from parameter studie日 made with the code.

The values finally arrived at are compromises because routine frequency response tests showed that considerable variation existed from event to event and between channels. This fact could account fo: some of the scatter that exists in the seismic data. For example, assume that the damping factors for Channels $A$ and $B$

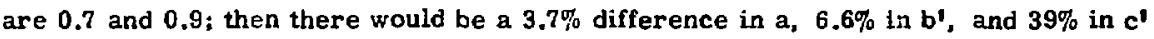




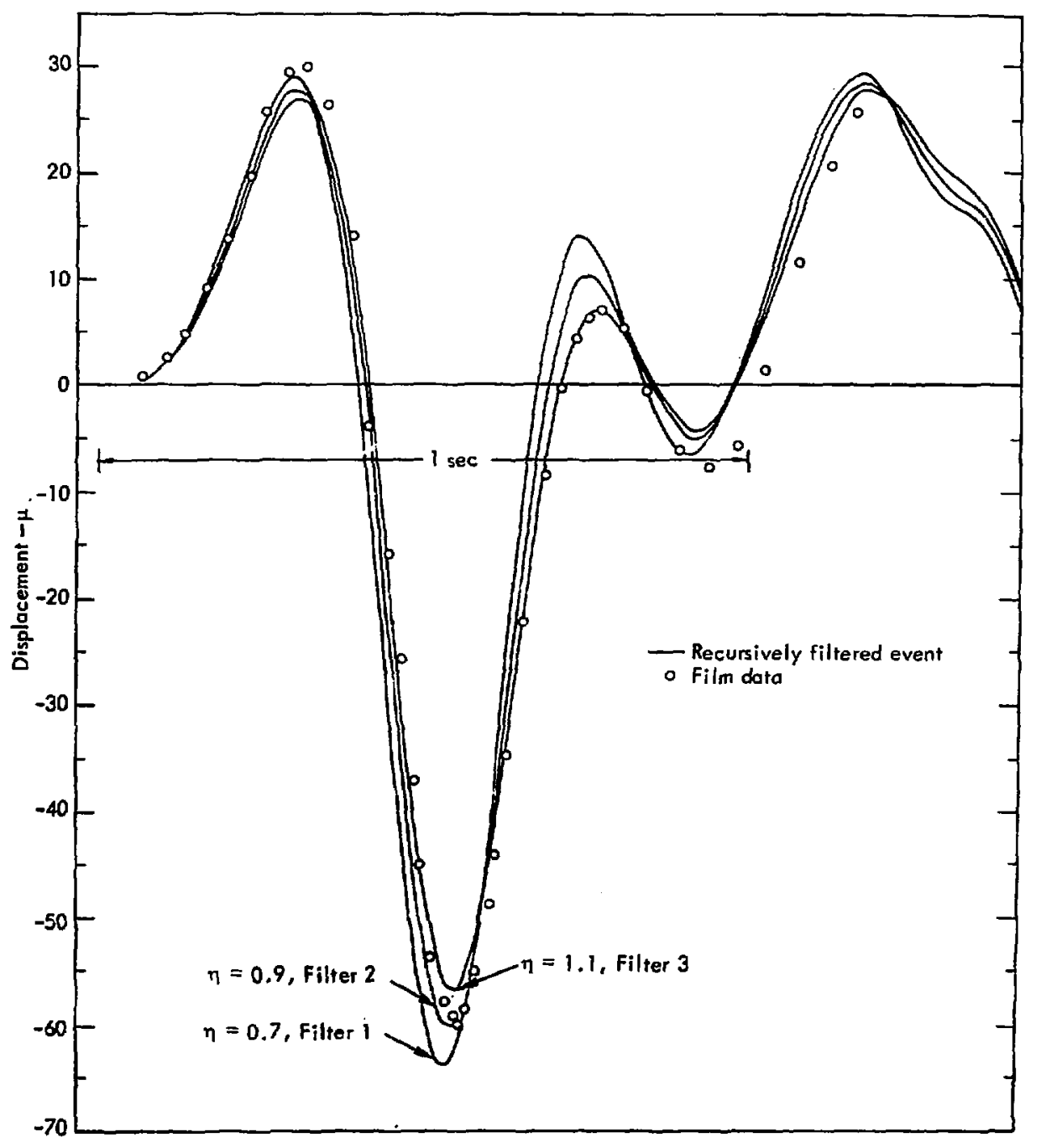

Fig. 16. Comparison for one event of the recursively filtered data with the film data Amplitudes are scaled to displacement in microns from system magnification at $1 \mathrm{~Hz}$. 
for the largest event in Table 14. This suggests that the present practice of measuring peak-to-peak should be discontinued because a poorly reproducible amplitude, $\mathbf{c}^{\prime}$, is receiving more weight than it deserves.

The recursion technique used in the code has the advantage that it can be used in an on-line mode of operation - should the funds for on-line digital processing of the data ever become available. The code is also better than an analog filter because once its parameters are specified, its frequency response does not change from time to time, as the analog filters have been known to do.

We have shown that the seismometer is effectively decoupled from the PTA galvanometer for the PTA attenuator values actually used to record events. Also, the damping of the galvanometer is unaffected at these high values of attenuation (24 $\mathrm{dB}$ and greater). However, this is not the case for small values of attenuation.

\section{Acknowledgments}

S. Bishop, J. Lamb, and C. Gallagher of the Electronics Engineering Department, and R. Scudero of the Mechanical Engineering Department performed many tests essential to this report. B. Howard of the Computations Department used his programming skills to write the recursive code. Finally, M. Heusinkveld guided and reviewed the document with a critical eye. 


\title{
Appendix \\ Benioff Recursive Filter
}

\author{
USE COMRLK \\ DIMENSION SAVEUF (?), SAVEF (2), STV (5),SFO (3), ABC (3) \\ EQuivalence (WORK,SAVEuF). (HCRK (3).SAVEF). (NORK(5), STV), \\ * \\ (WORK $(10), S F O),($ WORK $(13), A B C)$ \\ REAL MASS \\ DATA (HS $=.0096),(F$ OS $=1),,($ GENC $=355),,($ MASS $=107.5),($ OUCT $=6.97)$, \\ . \\ $(R D=61.5),(A T T=4$ ) $),(T G=79.42),(E R T=1),,(A G=.004),(F B G=5$.$) ,$ \\ (ETAF $=.9),(5 C A L E=202.415)$ \\ INI FORMAT $(12 F 5.0,510.0)$

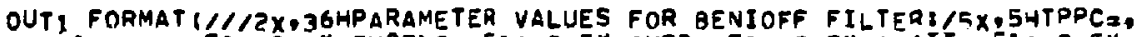

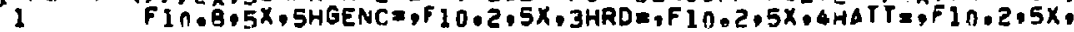 \\ $2 \quad 2 H S=, F$ i $0.5,5 X, 6 H S C A L E=, F 10,3 / 6 X_{1}, H F O S=, F 10,405 Y, 5 H O U C T=$, \\ $3 \quad F 1 \cap 04,5 X, 3 H T G=, F 10, C, 4 X, 5 H E T A F=, F 10,2 / 1)$ \\ OUT2 FORMAT $(3 x, 26$ HPEAK FILTERED AMPLITUDES $-, 4 x, 7 H C H A N N E L, R X, 1 H A, 14 X$, \\ $1 \mathrm{HB}, 14 X, 1 \mathrm{HC}, 12 \mathrm{X}, 6$ HOFFSET, $10 \mathrm{X}, 3$ HRMS) \\ OUT 3 FORMAT $\left(35 x \cdot 12 \cdot 3 x+5 E_{15.5}\right)$
}

NI IINSTF (ICNT+1)

$I C_{N T}=T C_{N T}+?$

N? =INSTR(TCNT)

TPPETIME IN SECONDS BETHEEN POINTS I" A CHANNEL HS \&MECHANICAL' DAMPI VS FACTOR FOS $=$ NATURAL FREQUENCY OF SEISMOMETER IN $+Z$ GENC=GENER ITOR CONSTANT IN NEWTONS PER AMP MASSAMASS OF SEISMOMETER IN KG DUCT = INDUCTANCE OF DATA COILS IN OHY RDEDAMPING RESISTANCE IN OHMS ATTEPTA ATTENUATOR SEITING IN DB TGEGALVANOMETER SENSITIVITY IN NT*U/AMP ERT =INERTIA OF GALVAVOMETER IN KG*M**? HGAMECHANICAL DAMPING FACTOR FQg $=$ NATURAL FRERUENCY OF GALVANOMETER ETAFADAMPING FACTOA FUR FILM RECORDER, DECIMAL SCALE PNORMALIZING FACTOR TVEPTA GALVANOMETER DEFLECTION OR VOLTASE OUTPUT CURV ICURAENT OUT OF SEISMOMETER

FOEPTA FILTER OUTPUT

FR=F ILM RECORDER OEFLECTION

C. COMPUTE FILTER CONSTANTS

IPP =TPP NCHANS OMS $=2 . *(3.1415927)$ WOS 


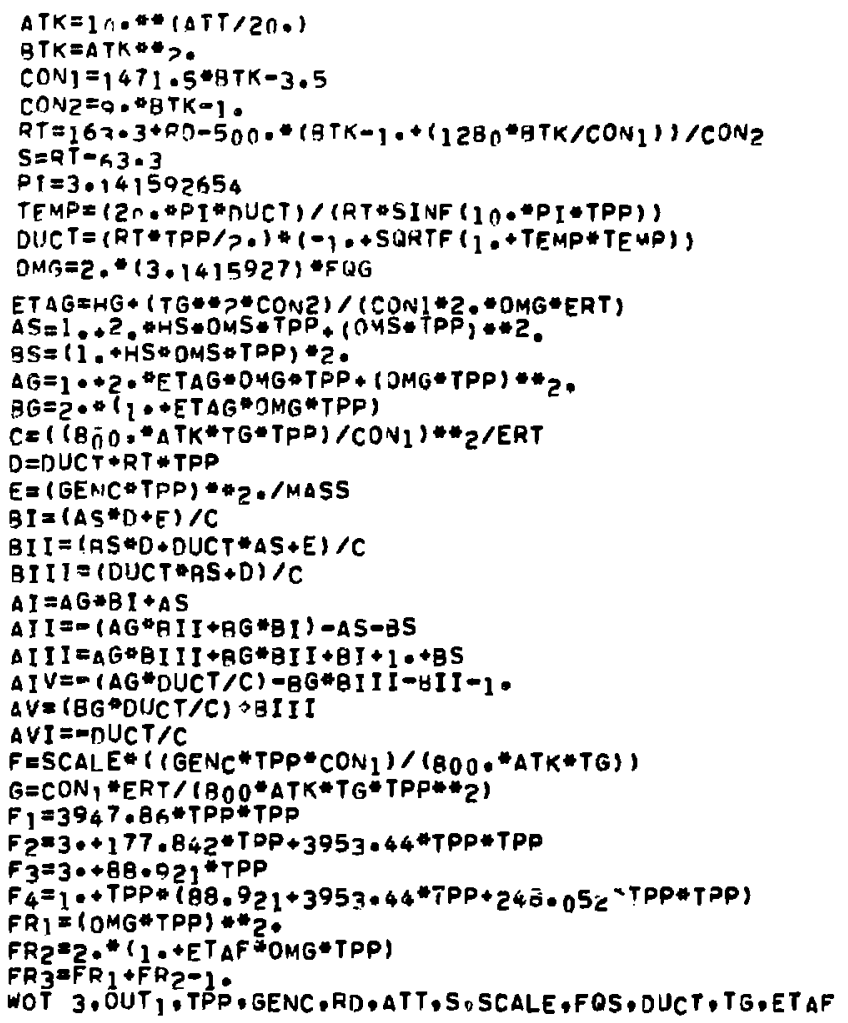

00200 NOCHEN1, V2

IF (ICOF (NOCH)) 200 ,

$\mathrm{N}_{3}=0$

$\operatorname{SAVEUF}(1)=\operatorname{SAVEUF}(2)=0$.

SAVEF (1) $=S A V E F(2) \geq 0$.

$0010 \quad I=1.5$

in STV(I) 50 . DO $15 I=1 \cdot 3$ 
30 DO 100 I =NOCH, NHBR N NGAVS

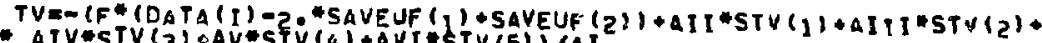

- AIV*STV (3) OAV *STV $(4)+A V I$ *STV (5)i/AI

$\left.F O=\left(F_{1} *\left(T V-S T V T_{1}\right)\right)+F_{2} * S F O(1)-F 3 * S F O(2) * 5 F O(3)\right) / F_{4}$

$F R=(F R] * F \cap+F R_{2}$ *SAVEF (1) -SAVEF (E)) /FR3

SAYEUF (2) $=$ SAVFUF (1)

SAVELF (I) =OATA (I)

SAVEF $(2)=$ SAVEF (1)

SAVEF (I) $=F R$

DO $50 \mathrm{~J}=5.2, \cdots$ ?

$50 \operatorname{STV}(J)=\operatorname{STV}(J-1)$

$\operatorname{stV}(1)=T V$

SFO(3:=SF:(z)

$S F O(2)=S F O(1)$

SFO (1) $=F O$

100 DATA $(1)=-F R$

CALL AMIMX (OATA (NOCH), NYBR, XMIN,XMAX, NCMANS)

IF (N3) 120,1120

$\operatorname{AMIN}(N D C H)=X M T N$

$\triangle M A X(N O C H)=X M A X$

$n_{3}=1$

60 TO 150

$120 \triangle M[N(N O C H)=M I N] F$ (AMIN (NOCH) \&XMIN)

$\triangle M A X(N O C H)$ =MAX]F (AYAX (NOCH) \&XMAX)

150 IF (IDAOSK=2) $200 \cdot 200$

CALL ADDSKWR ( 2 I OATA $A V X N, N M B R W, N T W, J F L A G)$

IF (IFLAG) 25 .

200 CONTINUE

TPPaTPP/NCHANS

FIND FILTERED PEAK AMPLITUDES

WOT 3.0UT?

NSR $=1 . / T P P$

NCNT $=\because N S R / N C H A V S$

DO 500 HOC.HaNI Q VE

IF (ICOR (NOCH), .500,

$A B C(1)=A B C(2)=A B C(3)=0$.

$X R A R E S T D=S V_{A R}=0$.

NPSINSR

LEI

IF (IDADSK-2) $225 \cdot .225$

$N X \approx_{0} * N M B R=N B A P T S \&$ ST $=$ NOADSK

210 CALL AOOSKRD (?I,OATA,NX,NMBR,NT,IFLAGI

225 GO TO $(250,300,350,400,450,400) \cdot 6$

250 NPS $=N D S-N M B R$

IF (NPS) $1490.49 \mathrm{R}$

NSTARTENMAR +NPS +NOCH

$J=n$ 


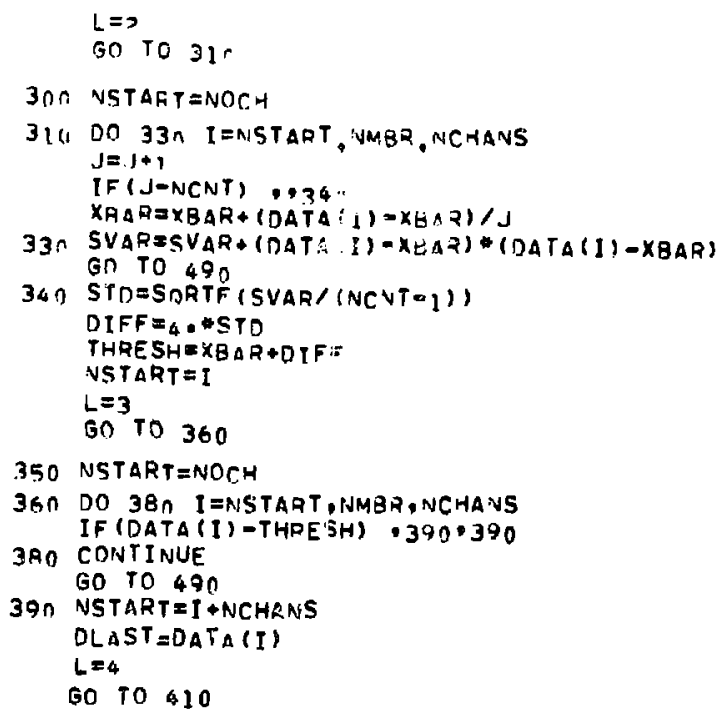

